Economia e Sociedade, Campinas, Unicamp. IE. http://dx.doi.org/10.1590/1982-3533.2021v30n2art11

\title{
Políticas de financiamento estudantil: análise de impacto do Fies no tempo de conclusão do ensino superior *
}

\author{
Kalinca Léia Becker ** \\ Mário Jorge Cardoso de Mendonça ***
}

\begin{abstract}
Resumo
Esse estudo avaliou o impacto do Fies no tempo total e no atraso da conclusão da educação superior dos alunos matriculados em cursos presenciais de instituições privadas, com base nas informações do Inep de 2007 a 2017 . O tempo de conclusão é o total de anos que o aluno esteve matriculado, já o atraso refere-se ao número de anos que o estudante levou para concluir o curso além do prazo mínimo de integralização. O impacto estimado por score de propensão do Fies no tempo total foi em torno de 4 meses. Os resultados da variável atraso também indicaram um impacto positivo, porém com menor intensidade e significativo apenas na primeira fase do programa, de 2000 a 2009. Também foram realizadas estimativas pelo método de Lewbel (2012), na tentativa de lidar com o possível viés das características não observáveis que influenciam a decisão individual de participar do Fies. Os resultados indicaram uma possível superestimação dos resultados quando não são consideradas as características não observadas dos alunos.
\end{abstract}

Palavras-chave: Crédito estudantil, Fies, Tempo de conclusão, Efeito Médio do Tratamento.

\begin{abstract}
Student funding policies: an analysis of the impact of Fies on the completion time of higher education

This study evaluated the impact of Fies (Brazilian funding program for students) on the total time and delay of the completion of higher education students enrolled in presential courses at private institutions based on information from INEP between 2007 and 2017. The total time is the number of years that the student was enrolled, whereas the delay refers to the number of years that the student took to complete the course beyond the minimum period of completion. The impact of Fies on the total time estimated by propensity score was around 4 months. The results of the delay variable also suggested a positive impact, but less intense and only significant in the first stage of the program, that is, from 2000 to 2009 . Estimates were also made using the Lewbel method (2012), in an attempt to deal with the possible bias of unobservable characteristics that influence the individual decision to apply for Fies. The analysis showed a possible overestimation of the results when the unobserved characteristics of the students are not considered.
\end{abstract}

Keywords: Education funding, Fies, Completion time, Average Treatment Effect.

JEL: D22, H52, I21.

\section{Introdução}

O atraso na conclusão do ensino superior é um problema recorrente em vários países do mundo, conforme evidenciado na revisão de literatura de Garibaldi et al. (2012). No Brasil, dos alunos de instituições privadas que realizaram o Exame Nacional de Desempenho de Estudantes (Enade), entre 2015 e 2017, aproximadamente 18\% concluíram o curso em 6 anos ou mais. Estender o tempo de diplomação implica em custo de oportunidade devido ao impedimento, ainda que parcial, de obter

\footnotetext{
* Artigo recebido em 27 de maio de 2019 e aprovado em 31 de julho de 2020.

** Professora no Departamento de Economia e Relações Internacionais na Universidade Federal de Santa Maria (UFSM), Santa Maria, RS, Brasil. E-mail: kalinca.becker@ufsm.br. ORCiD: https://orcid.org/0000-0002-6896-9411.

${ }^{* * *}$ Técnico de Planejamento e Pesquisa da Diretoria de Estudos e Políticas Regionais, Urbanas e Ambientais (Dirur) do Instituto de Pesquisa Econômica Aplicada (Ipea), Rio de Janeiro, RJ, Brasil. E-mail: mario.mendonca@ipea.gov.br. ORCiD: https://orcid.org/00000003-1002-6725.
} 
renda por meio do trabalho e dos ganhos salariais associados ao diploma do ensino superior. Além disso, o atraso na conclusão do curso pode levar à depreciação do capital humano já adquirido e também prejudicar a disputa de vaga no segmento do mercado de trabalho pretendido pelo indivíduo.

Os motivos pelos quais os alunos atrasam a conclusão curso são variados e podem estar associados às preferências individuais de alocação do tempo, à expectativa de retorno à educação, à aversão ao risco e ao gosto pela educação (Cameron; Taber, 2004). Outro fator importante que pode levar o aluno a atrasar a conclusão do curso é a restrição orçamentária. Obter financiamento para cursar a educação superior é essencial para a permanência e para a conclusão do curso no período regular, principalmente na ausência de recursos familiares. Porém, os mercados de crédito para investimento em educação são imperfeitos, uma vez que o capital humano não pode ser oferecido como colateral, seja na forma de trabalho, seja na forma de habilidades futuras (Becker, 1962; Becker, 1967; Ljungqvist, 1993; Rocha, 2014).

Diante disso, muitos países do mundo possuem sistemas de financiamento e crédito estudantil para o ensino superior, que contribuem para aumentar as taxas de conclusão (Desjardins et al., 2002; Dynarski, 2003; Elsayed, 2016). Porém, é importante que a política tenha mecanismos para incentivar que o aluno conclua o curso no tempo regular, uma vez que, conforme destacado por Arendt (2013), a ajuda financeira, por tornar menos dispendioso permanecer na educação, pode aumentar o tempo de conclusão, o que levaria a um efeito contrário ao desejado.

Nesse mesmo sentido, Garibaldi et al. (2012) argumentam que o atraso na conclusão do curso geralmente acontece em contextos em que os custos do ensino superior não aumentam para os alunos que permanecem no curso além do tempo regular. Usando dados da Universidade Bocconi, na Itália, e regressões descontínuas, com base no fato de que alunos com menor renda familiar pagam uma menor taxa de matrícula, os autores observaram que um aumento de 1.000 euros nessa taxa para os alunos do último ano do curso reduz a probabilidade de graduação tardia em 5,2\%.

No Brasil, uma das políticas de financiamento do ensino superior, voltada para alunos matriculados em instituições privadas com restrições orçamentárias, é o Fundo de Financiamento ao Estudante do Ensino Superior (Fies), implementado pelo governo federal no ano 2000. Como essa ajuda financeira é concedida na forma de empréstimo, é possível que incidência dos juros sobre a dívida funcione como uma forma de incentivo para a conclusão do curso no tempo regular. Porém, a reformulação da política no ano 2010 levou a um afrouxamento nas regras de concessão do financiamento e um aumento das facilidades de pagamento do empréstimo, o que pode ter reduzido os incentivos para concluir o curso no tempo regular.

Nesse contexto, o estudo pretende avaliar o impacto do Fies no tempo total e no atraso na conclusão do curso dos alunos matriculados em cursos presenciais de instituições privadas nas duas primeiras fases da política, de 2000 a 2009 e de 2010 a 2014. Para isso, estima-se o efeito médio do tratamento nos tratados (ATT), por meio dos métodos de pareamento por score de propensão e por entropia, que utilizam as características observáveis dos estudantes para construir o contrafactual (estudantes que não receberam o Fies). Na tentativa de lidar com o possível viés das características não observáveis que influenciam a decisão individual de participar do Fies, serão também realizadas estimativas pelo método de Lewbel (2012), que consiste em explorar a heterocedasticidade dos erros 
no primeiro estágio da regressão para gerar instrumentos internamente. Os dados são dos estudantes que realizaram o Enade nos anos de 2007 a 2017.

\section{Políticas de crédito para a educação superior e seus efeitos sobre os resultados escolares dos alunos}

Conforme Dynarski (2003), existem três razões principais para a intervenção no mercado de crédito para a educação superior. A primeira, e talvez a mais discutida na literatura, é que os estudantes com restrições orçamentárias e que não tiverem acesso aos mercados de crédito, investirão menos em educação. Muitos estudos evidenciam a relação entre o baixo investimento em educação e as restrições orçamentárias da família e ao crédito (Loury, 1981; Becker; Tomes, 1986; Jacoby, 1994; Belley; Lochner, 2007; Lochner; Monge-Naranjo, 2011). Isso implica que os resultados educacionais serão determinados não apenas pelos custos e benefícios do investimento, mas também pelas desigualdades preexistentes nos recursos familiares (Melguizo et al., 2016).

A segunda razão é a incerteza dos estudantes sobre os custos e benefícios da graduação, uma vez que o retorno à escolaridade pode mudar ao longo do tempo, devido a choques agregados no mercado de trabalho ou choques idiossincráticos no retorno de um ano a mais de educação ou de uma determinada especialização. Além disso, um estudante pode estar incerto sobre sua capacidade de concluir até mesmo um ano da faculdade. Se o retorno de um ano de faculdade é incerto, então, mesmo na ausência de restrições de liquidez, os indivíduos avessos ao risco investirão menos em educação. Se o governo é menos avesso ao risco do que os indivíduos, uma concessão para os custos de escolarização terá efeitos positivos no bem-estar (Dynarski, 2003).

Finalmente, a terceira razão é que a educação produz externalidades positivas, gerando retornos privados e sociais em várias dimensões, como maior produtividade e menor criminalidade, conforme evidenciado na revisão de literatura de Barbosa-Filho e Pessoa (2010). No Brasil, o rendimento médio dos trabalhadores com graduação é $185 \%$ maior daqueles que apenas completaram a Educação Básica. Assim, os gastos do governo com os programas de subsídio ao ensino superior podem ser compensados pelo aumento da arrecadação de impostos sobre a renda das pessoas mais escolarizadas.

Diante disso, os governos de muitos países promovem políticas públicas e intervenções no mercado de crédito para o financiamento da educação superior. Nos EUA, conforme Dynarski (2003) e Angrist et al. (2014), todo ano agências do governo e grupos privados distribuem bilhões de dólares em programas de financiamento para estudantes do ensino superior. O programa público de crédito educativo mais conhecido e que possui o maior número de beneficiários é o Stafford Loan, voltado para todos os estudantes de graduação e de pós-graduação. As modalidades de crédito subsidiado e não-subsidiado diferem em relação ao auxílio concedido pelo governo federal no pagamento dos juros do empréstimo, cujo montante também deve ser pago. Estudantes com maior necessidade financeira podem pleitear uma modalidade do empréstimo em que os juros são pagos apenas ao final do curso, o chamado subsidized loan. Na outra modalidade, o estudante paga os juros do empréstimo enquanto está cursando a graduação (Resende, 2018). 
Desjardins et al. (2002) analisaram o processo temporal de evasão com base em uma amostra dos alunos matriculados na Universidade de Minnesota. Os resultados indicaram que as bolsas e ajudas financeiras reduzem a probabilidade de trancar o curso e aumentam a probabilidade de conclusão. No mesmo sentido, empregando o método de propensity score matching, Elsayed (2016) observou que a concessão de benefícios fiscais aumenta em 8 pontos percentuais a probabilidade de o estudante concluir o ensino superior.

Já Dynarski (2003) analisou uma mudança na política de auxílio financeiro no início dos anos 80, que eliminou o Programa Social Security Student Benefit, para identificar o efeito desse auxílio na frequência e conclusão do ensino superior, estimando um modelo de diferenças-em-diferenças. Os resultados indicaram que a eliminação do programa de auxílio reduziu a probabilidade de frequência em mais de um terço. De maneira análoga, a oferta de subsídio aumentou a probabilidade de frequência e conclusão do ensino superior.

Arendt (2013) analisou uma reforma em grande escala do sistema de concessão e empréstimo estudantil dinamarquês em 1988 que, entre outras medidas, aumentou os subsídios para estudantes em 57\%. Os resultados indicaram que a reforma reduziu as taxas de abandono escolar, mas não teve um efeito global nas taxas de conclusão, embora com uma variação substancial entre os subgrupos da população. O impacto sobre as taxas de abandono escolar foi mais elevado para os estudantes de origem socioeconômica mais baixa e o impacto nas taxas de conclusão foi mais elevado três anos após o tempo regular de conclusão.

Angrist et al. (2014) analisaram um grande programa aleatório de bolsas de estudos financiado pelo setor privado para estudantes de faculdades e universidades públicas de Nebraska. Os resultados indicaram que a ajuda financeira impulsionou as matrículas e a permanência dos alunos. Destaca-se que o auxílio oferecido aos candidatos não brancos, com desempenho acadêmico relativamente baixo, gerou os maiores resultados nas taxas de matrícula e permanência.

$\mathrm{Na}$ América Latina também se observam algumas experiências positivas das políticas de auxílio financeiro aos estudantes da graduação. A Colômbia foi pioneira ao institucionalizar os programas de financiamento estudantil como política pública em 1950. Em 2002 o governo colombiano implementou o programa de crédito estudantil ACCES (Acceso con Calidad a la Educación Superior) para estudantes de baixa renda. Melguizo et al. (2016) avaliaram o impacto desse programa usando regressões descontínuas com base nos pontos de corte dos critérios de elegibilidade do empréstimo. Os resultados indicaram que o ACCES contribuiu para o aumento da taxa de matrícula, diminuição da taxa de evasão e aumento do desempenho acadêmico.

No Chile, cerca de $85 \%$ dos estudantes estão matriculados em instituições de ensino superior privadas e o programa de financiamento atualmente vigente no país é o Crédito con Aval del Estado (CAE). Rau et al. (2012) estimaram um modelo estrutural de decisões sequenciais de escolaridade para avaliar o impacto do CAE sobre a evasão e o desempenho no mercado de trabalho dos seus beneficiários. Os resultados indicaram que o CAE tem um efeito positivo na redução das taxas de evasão, principalmente dos alunos de famílias de baixa renda. No entanto, os beneficiários do CAE têm salários mais baixos, o que os autores atribuem a um problema de incentivo no desenho do programa, que pode levar as instituições de ensino superior a reduzir a qualidade educacional. 


\section{Fies}

O Fies é um programa do Ministério da Educação para a concessão de crédito aos estudantes regularmente matriculados nos cursos superiores de instituições de ensino privadas. O programa foi implementado pela Lei n. 10.260/2001 e passou por grandes reformulações ao longo dos anos. Conforme Resende (2018), o histórico do Fies pode ser organizado em três fases principais, descritas no Quadro 2. Para cada etapa do programa Fies, esse quadro indica as suas principais características quanto às condições de pagamento e elegibilidade. A primeira fase, de 2000 a 2009, caracterizou-se pela consolidação da política, com clara preocupação com a inadimplência e com o equilíbrio fiscal.

Quadro 2

Principais características do Fies

\begin{tabular}{|c|c|c|c|c|}
\hline & & $\begin{array}{c}\text { Primeira Fase } \\
2000-2009 \\
\end{array}$ & $\begin{array}{c}\text { Segunda Fase } \\
2010-2014 \\
\end{array}$ & $\begin{array}{c}\text { Terceira Fase } \\
2015-2017 \\
\end{array}$ \\
\hline \multirow{4}{*}{ 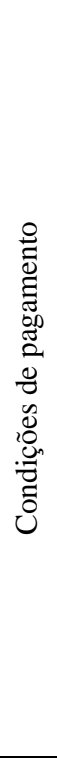 } & Taxa de juros & $\begin{array}{c}\text { Até } 2006: 9 \% \\
\text { De } 2006 \text { a } 2009: 3,5 \% \text { a } 6,5 \% \\
\text { De 2009 a } 2010: 3,5 \%\end{array}$ & $3,4 \%$ a.a. & $6,5 \%$ a.a. \\
\hline & Carência & $\begin{array}{c}\text { Até 2007: não havia carência, } \\
\text { o estudante começava a pagar } \\
\text { no mês seguinte ao } \\
\text { encerramento do contrato } \\
2007 \text {-2009: } 6 \text { meses a partir } \\
\text { do mês subsequente à } \\
\text { conclusão do curso }\end{array}$ & $\begin{array}{c}18 \text { meses a partir do mês } \\
\text { subsequente à conclusão } \\
\text { do curso }\end{array}$ & $\begin{array}{c}18 \text { meses a partir do mês } \\
\text { subsequente à conclusão } \\
\text { do curso }\end{array}$ \\
\hline & $\begin{array}{l}\text { Prazo de } \\
\text { amortização do } \\
\text { contrato }\end{array}$ & $\begin{array}{c}\text { Até 2010: } 2 \text { vezes a duração } \\
\text { do curso }\end{array}$ & $\begin{array}{l}3 \text { vezes a duração do curso } \\
+12 \text { meses }\end{array}$ & $\begin{array}{c}3 \text { vezes a duração do } \\
\text { curso }\end{array}$ \\
\hline & $\begin{array}{l}\text { Pagamento de } \\
\text { juros } \\
\text { trimestrais } \\
\text { (utilização e } \\
\text { carência) } \\
\end{array}$ & Sem reajuste desde 2009 & $\mathrm{R} \$ 50,00$ & Até R \$150,00 \\
\hline \multirow{3}{*}{ 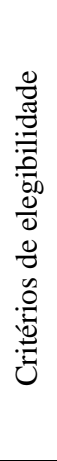 } & Renda familiar & Não havia menção ${ }^{a}$ & Até 20 salários mínimos ${ }^{\mathrm{b}}$ & $\begin{array}{l}\text { 2015: } 2,5 \text { salários- } \\
\text { mínimos per capita } \\
\text { 2016: } 3 \text { salários- } \\
\text { mínimos per capita }\end{array}$ \\
\hline & Nota Enem & Não havia menção & $\begin{array}{l}\text { Ter realizado o Enem no } \\
\text { ano anterior }\end{array}$ & $\begin{array}{c}\text { Nota mínima de } 450 \\
\text { pontos na média do } \\
\text { Enem e nota diferente de } \\
\text { zero na redação }\end{array}$ \\
\hline & Nota SINAES & Não havia menção & Conceito de qualidade 3 & $\begin{array}{l}\text { Prioritariamente IES } \\
\text { com conceito de } \\
\text { qualidade } 5\end{array}$ \\
\hline
\end{tabular}

Notas:

(a) O financiamento não poderia ser concedido ao estudante cujo percentual de comprometimento da renda familiar mensal bruta per capita fosse inferior a $20 \%$.

(b) O comprometimento da renda familiar mensal bruta per capita deveria ser superior a $20 \%$.

Fonte: Resende (2018). 
A segunda fase, de 2010 a 2014, caracterizou-se por um afrouxamento das regras de concessão do financiamento e aumento das facilidades de pagamento do empréstimo, como menor taxa de juros e maior prazo para amortização. Esse afrouxamento pode ter reduzido os incentivos para a diplomação no tempo regular, uma vez que a redução dos custos de permanecer mais um ano no curso pode aumentar o tempo de conclusão (Garibaldi et al., 2012; Arendt, 2013). Além disso, a facilidade para obtenção de crédito ocorrida na segunda fase gerou efeitos na inadimplência. Segundo as projeções feitas com base nos fluxos financeiros dos contratos daqueles que ingressaram no programa entre o primeiro semestre de 2010 até o segundo semestre de 2016, o efeito total de perdas por inadimplência, subsídio implícito e despesa administrativa alcançará cerca de R \$11,1 bilhões em 2024 (Ministério da Fazenda, 2017).

Outra mudança nas regras do Fies nessa etapa foi que as inscrições passaram a ser feitas em fluxo contínuo, permitindo ao estudante solicitar o financiamento em qualquer período do ano. Também foram estabelecidos critérios de elegibilidade com base na renda familiar (até 20 saláriosmínimos) e qualidade do curso, mensurada por meio dos processos conduzidos pelo Ministério da Educação (conceito acima de 3).

Assim, as matrículas Fies passaram de aproximadamente 5\% do total das matrículas na rede privada em 2009 para $39 \%$ em 2015 . Porém, esse crescimento se deu em um ritmo incompatível com a disponibilidade de recursos no médio e longo prazo, e com a transferência de uma parcela relevante dos riscos de financiamento ao setor público (Ministério da Fazenda, 2017). Além disso, Duarte e Mello (2014) evidenciaram que as mudanças nas regras do programa em 2010 causaram um aumento nas mensalidades.

Nesse contexto, em 2015, o Fies passou por importantes mudanças, iniciando a terceira fase do programa, caracterizada por alterações estruturais com o objetivo de adequar as regras às restrições fiscais vigentes e contribuir para a sustentabilidade da política. A partir do segundo semestre de 2015, os financiamentos concedidos com recursos do Fies passaram a ter taxa de juros de $6,5 \%$ a.a. Os critérios de elegibilidade também se tornaram mais restritivos. Tais reformulações levaram a uma redução de $61 \%$ na oferta de novos contratos de financiamento entre 2014 e 2015 (Resende, 2018).

Em 2018 a política foi novamente reestruturada, ainda com o objetivo de tornar a concessão mais sustentável do ponto de vista das finanças públicas. Houve também modificações no sentido de facilitar o acesso ao crédito para aqueles que mais precisam, de modo que foi criada uma modalidade com taxa de juros real zero para estudantes com renda familiar per capita de até 3 salários-mínimos. A outra modalidade de financiamento é destinada aos estudantes com renda familiar per capita de até cinco salários-mínimos e conta com recursos públicos e, também, de bancos privados. Essa nova fase foi denominada de Novo Fies.

\section{Metodologia}

O propósito deste estudo é estimar o efeito causal do Fies sobre o tempo total e o atraso na conclusão do curso de graduação (em anos), com base nas informações dos estudantes matriculados em cursos presenciais de instituições que realizaram o Enade entre 2007 e 2017. Para avaliar o efeito de uma política sobre os indivíduos tratados (aqueles que estão inscritos no Fies nessa base de dados), 
o ideal seria observar esses mesmos indivíduos na ausência dessa política. A metodologia padrão para formalizar este problema consiste na abordagem de resultado potencial (Rubin, 1974).

Seja $S_{i}$ um indicador de tratamento para o aluno $i$ que assume o valor igual a um, no caso de ter recebido o Fies, e zero, caso contrário. O resultado potencial para o tempo total ou atraso na conclusão do curso de graduação é definido como sendo $Y_{i}\left(S_{i}\right)$ para cada aluno $i$, onde $i=1, \ldots N$, com $N$ denotando a população total. $\mathrm{O}$ efeito de tratamento para um indivíduo $i$ pode ser escrito como:

$$
\beta_{i}=Y_{i}(1)-Y_{i}(0)
$$

O problema de avaliação fundamental surge devido ao fato de que apenas um dos resultados potenciais é observado. O resultado não observado é chamado de contrafactual. Portanto, a estimação do efeito do tratamento individual $\beta_{i}$ não é possível, devendo o investigador se concentrar nos efeitos médios do tratamento (população). Assim, para estimar essa medida, toma-se como referência o efeito médio do tratamento nos tratados, $\beta_{\text {ATT }}$, de modo que:

$$
\beta_{\text {ATT }}=E\left[Y_{i}(1) \mid S=1\right]-E\left[Y_{i}(0) \mid S=1\right]
$$

Como a média contrafactual $E\left[Y_{i}(0) \mid S=1\right]$ para os tratados não é observada, é preciso escolher um substituto adequado para estimar $\beta_{A T T}$. O emprego do resultado médio dos indivíduos não tratados, $E\left[Y_{i}(0) \mid S=0\right]$, não resolve a questão, pois é provável que os fatores que determinam a decisão de tratamento também determinam a variável de interesse resultante, $Y_{i}\left(S_{i}\right)$. Neste caso, os resultados para os indivíduos do grupo de tratamento e de comparação iriam diferir mesmo na ausência do tratamento, levando ao chamado "viés de auto-seleção". Assim, é necessário encontrar um contrafactual, ou seja, um grupo que represente qual teria sido o comportamento dos tratados na ausência do tratamento.

Para tratar esse problema serão utilizados dois métodos, o pareamento com escore de propensão, que estima probabilidade de o indivíduo ser tratado com base nas características observáveis, e o pareamento por entropia, que consiste em um esquema de reponderação (reweighting scheme) do grupo de controle para coincidir com os momentos do grupo de tratamento e, assim, alcançar um nível de balanceamento desejável para as distribuições das variáveis nesses grupos, ponderando as informações por meio de um conjunto de condições associadas aos momentos dessas distribuições.

Ambos os métodos se baseiam nas características observáveis dos estudantes para construir o contrafactual. Porém, para o recebimento Fies, é necessário que o indivíduo faça a solicitação, sendo contemplados aqueles que cumprirem os critérios de elegibilidade descritos no Quadro 1. Um tratamento que não é aleatório e a possiblidade de haver variáveis omitidas que influenciam a decisão de se inscrever no programa e, também, os resultados, podem levar a estimativas viesadas do efeito do tratamento.

Assim, na tentativa de lidar com o possível viés das características não observáveis, o efeito do Fies sobre o tempo e o atraso na conclusão do curso também será estimado pelo método de Lewbel (2012), que consiste em explorar a heterocedasticidade dos erros no primeiro estágio da regressão para gerar instrumentos internamente. Embora essa técnica forneça estimativas menos confiáveis, o 
método tem produzido resultados semelhantes aos obtidos por meio de estimações com os instrumentos tradicionais (Emran; Hou, 2013; Tigre et al., 2016).

No Brasil, Souza et al. (2019) empregaram o método de Lewbel para avaliar o impacto do Programa Bolsa Família sobre o trabalho infantil na tentativa de lidar com o problema da endogeneidade da renda familiar. Os resultados indicaram que o Bolsa Família pode reduzir a entrada precoce de crianças no mercado de trabalho, o que, conforme os autores, reforça a hipótese de que variáveis omitidas podem viesar os resultados de estudos do impacto do Programa sobre o trabalho infantil.

\subsection{Pareamento com escore de propensão (Propensity score matching)}

De modo a encontrar o grupo contrafactual, será utilizada, primeiramente, a técnica de pareamento com escore de propensão, que é uma técnica bastante utilizada na literatura para encontrar um grupo de comparação similar ao tratamento com base nas características observáveis dos indivíduos que afetam a probabilidade de ser tratado (Rosenbaum; Rubin, 1983).

Essa técnica representa uma evolução em relação ao pareamento puro, no qual cada unidade do grupo dos tratados é obtida a partir da comparação com unidades não tratadas, de modo a encontrar um "par" para a referida unidade tratada. Esse pareamento depende de características observadas para construir um grupo de comparação e baseia-se na suposição de que as características não observadas, tanto no grupo de tratamento como nos não tratados, não tem efeito sobre os resultados de interesse. O pareamento é um método não experimental usado para construir um grupo de comparação artificial, identificando, para cada observação do grupo tratamento, uma observação de não tratamento (ou um conjunto de observações de não tratamento) com as características semelhantes.

No entanto, encontrar uma boa correspondência para cada elemento tratado exige uma correspondência mais próxima possível dos determinantes da decisão do indivíduo de se inscrever no programa. Se a quantidade de características relevantes observadas for muito grande, pode ser difícil identificar uma correspondência para cada uma das unidades no grupo de tratamento. No entanto, caso o pareamento seja feito com um número pequeno de variáveis, é bem provável que não se encontre uma boa correspondência para os inscritos no programa. Portanto, temos uma difícil escolha quando fazemos uso do pareamento puro.

Na metodologia de pareamento por escore de propensão não é necessário comparar cada unidade tratada com seu par não tratado. Em vez disso, para cada unidade no grupo de tratamento e controle, calcula-se a probabilidade de se inscrever no programa, com base características observáveis, o que se denomina por escore de propensão. Esta pontuação, inserida no intervalo $(0,1)$, resume todas as características observadas das unidades, uma vez que influenciam a probabilidade de se inscrever no programa. Tendo calculado o escore de propensão para todas as unidades, as unidades do grupo de tratamento podem ser combinadas com aquelas pertencentes ao grupo dos não tratados que possuem o escore de propensão mais próximo. As "unidades mais próximas" se tornam grupo de comparação e são usadas para produzir uma estimativa do contrafactual.

Mais especificamente, para estimar $\beta_{A T T}$ é preciso encontrar indivíduos pertencentes aos grupos tratados e de controle que possam ser comparados, depois de ajustadas as características 
observadas para cada indivíduo $i$ associadas a um vetor $X_{i}=\left[X_{i 1, \ldots,} X_{i N}\right]$, onde $X_{i j}$ é a característica $j$ do indivíduo $i$. Considera-se ainda a hipótese de independência condicional

$$
Y(1), Y(0) \perp S \mid X \text {, para } \forall X
$$

Essa hipótese implica que a seleção é baseada unicamente nas características observáveis e que todas as variáveis que influenciam simultaneamente a atribuição do tratamento e os resultados potenciais são observadas, o que naturalmente é uma hipótese bastante forte. Deve-se ainda considerar que o pareamento se torna cada vez mais problemático à medida que a dimensionalidade de $X$ aumenta ${ }^{1}$. Rosenbaum e Rubin (1983) sugerem as chamadas pontuações de balanceamento. Conforme os autores, se os resultados potenciais são independentes do tratamento, condicional à $X$, então eles também são independentes do tratamento, condicional a um balanceamento $b(X)$.

O escore de propensão, $p(S=1 \mid X)=P(X)$, é a probabilidade de o indivíduo participar do tratamento (no caso, o aluno ser inscrito no Fies) dado os fatores observados $X$, de modo que a hipótese de independência condicional deve ser reescrita como:

$$
Y(1), Y(0) \perp S \mid P(X) \text {, para } \forall X
$$

Assim é possível encontrar o efeito do tratamento para cada valor de $X_{i}$ por meio da diferença das médias de $Y(1)$ e $Y(0)$ (Rosenbaum e Rubin, 1985). Dessa forma, a equação (2) pode ser reescrita como:

$$
\beta_{\text {ATT }}=E\left\{E\left[Y_{i} \mid p\left(X_{i}\right), S_{i}=1\right]-E\left[Y_{i} \mid p\left(X_{i}\right), S_{i}=0\right]\right\}
$$

Estima-se $p\left(X_{i}\right)$ por meio do modelo probit. Para o pareamento entre os alunos tratados (Fies) e não tratados (não Fies) são utilizados três algoritmos: 1 vizinho mais próximo, 5 vizinhos mais próximos, e kernel matching (uma pessoa tratada comparada com uma ponderação das pessoas do controle). Para avaliar a qualidade do pareamento são utilizados os testes propostos por Dehejia e Wahba (2002). Os valores do Pseudo- $\mathrm{R}^{2}$ próximos a zero indicam que o modelo tem menor poder para explicar a condição de tratamento, evidenciando uma boa qualidade do pareamento. Uma evidência adicional é a não significância conjunta dos regressores no teste da Razão de Verossimilhança $(L R)$. A qualidade do pareamento pode ser também observada pela redução do viés após o matching, dado pela diferença de média e de mediana entre as características observáveis do grupo controle e tratamento. Adicionalmente, analisa-se a diferença nas médias das covariadas antes e depois do pareamento.

Para que o pareamento com escore de propensão possa ser aplicado, além da hipótese de independência condicional, são necessárias algumas condições adicionais. Primeiro, é necessário que todas as unidades tratadas tenham correspondência com alguma unidade não tratada. Contudo, pode acontecer que existam unidades tratadas que não encontrem nenhuma unidade no grupo de não tratados com escore de propensão semelhantes. Em outras palavras, pode existir uma "falta de suporte apoio comum", ou pouca sobreposição entre os escores de propensão do grupo tratamento e aqueles do grupo não tratado. Segundo, deve-se assegurar que não há diferenças sistemáticas nas características das unidades de tratamento e controle, além de exigir um conjunto extenso de dados.

(1) O que é conhecido como maldição da dimensionalidade. 
Hainmueller (2012) ressalta ainda que, ao estimar os escores de propensão, muitas vezes, é difícil balancear conjuntamente todas as covariadas, sendo necessário utilizar a iteração até que uma solução de balanceamento satisfatória seja atingida.

\subsection{Pareamento por entropia}

O pareamento por entropia é um procedimento que permite alcançar um nível de balanceamento desejável para distribuições das variáveis nos grupos de tratamento e controle, ponderando as informações por meio de um conjunto de condições associados aos momentos dessas distribuições. Conforme Hainmueller (2012), o método consiste em um esquema de reponderação que atribui um peso escalar a cada unidade de amostra, de forma que os grupos reponderados satisfaçam um conjunto de restrições de balanceamento que são impostas aos momentos das distribuições de covariadas.

Assim, considerando que o objetivo da análise é reponderar o grupo de controle para coincidir com os momentos do grupo de tratamento, a média do contrafactual pode ser estimada por:

$$
E\left[Y^{0} \mid S=0\right]=\frac{\sum_{(i \mid S=0)} Y_{i} w_{i}}{\sum_{(i \mid S=0)} w_{i}}
$$

onde $w_{i}$ é um peso escolhido para cada unidade de controle. Os pesos são escolhidos pelo seguinte esquema de reponderação:

$$
\min _{w_{i}} H(w)=\sum_{(i \mid S=0)} h\left(w_{i}\right)
$$

Sujeito às restrições de equilíbrio e normalização

$$
\begin{gathered}
\sum_{(i \mid S=0)} w_{i} C_{r i}\left(X_{i}\right)=m_{r} \quad \operatorname{com} r \in 1, \ldots, \mathrm{R} \\
\sum_{(i \mid S=0)} w_{i}=1
\end{gathered}
$$$$
w_{i} \geq 0 \text { para todo } i \text { tal que } S=0
$$

onde $q_{i}=1 / n_{0}$ é o peso base e $C_{r i}\left(X_{i}\right)=m_{r}$ descreve um conjunto de $R$ restrições de balanceamento impostas aos momentos das covariáveis do grupo de controle reponderado. Uma típica restrição de balanceamento pode ser formulada de modo que $m_{r}$ contenha o momento de uma determinada covariável $X_{j i}$ do grupo de tratamento e as funções de momento para o grupo de controle são especificadas como $c_{r i}\left(X_{i j}\right)=X_{i j}^{r}$ ou $c_{r i}\left(X_{i j}\right)=\left(X_{i j}^{r}-\mu_{j}\right)^{r}$ com média $\mu_{j}$.

O balanceamento por entropia, conforme aponta Hainmueller (2012), tem a vantagem de ajustar diretamente os pesos unitários aos momentos amostrais, garantindo que o balanceamento melhore para todos os momentos amostrais incluídos na reponderação. 


\subsection{Método de Lewbel}

Conforme descrito anteriormente, os métodos de pareamento por escore de propensão e entropia baseiam-se na hipótese de independência condicional das características observáveis. Essa hipótese implica que, uma vez controladas essas características, os indivíduos de cada grupo possuem a mesma probabilidade de receber o Fies. Esta é uma hipótese forte, mesmo considerando que a base de dados do Enade fornece uma série de características dos estudantes que podem afetar tanto o tratamento (Fies) quanto o resultado (tempo e atraso na conclusão do curso), conforme descrito no Quadro 1 da seção 5, a seguir.

$\mathrm{Na}$ tentativa de lidar com o possível viés das características não observáveis que influenciam a decisão individual de participar do Fies, serão também realizadas estimativas pelo método de Lewbel (2012). Sejam y e $S$ variáveis endógenas e um vetor de variáveis exógenas $X$ cujo processo gerador é definido pelas seguintes equações:

$$
\begin{gathered}
y=X^{\prime} \beta+\gamma S+\varepsilon_{1} \\
S=X^{\prime} \alpha+\varepsilon_{2}
\end{gathered}
$$

onde os distúrbios $\varepsilon_{1}$ e $\varepsilon_{2}$ podem ser correlacionados. $\mathrm{O}$ método de variáveis instrumentais padrão para estimar $\gamma$ e $\beta$ consiste em encontrar um elemento de $X$ que aparece em $S$, mas não em $y$ e empregar esse regressor excluído como instrumento para $S$. O problema de identificação é que, possivelmente, nenhum elemento de $X$ possa ser excluído da equação $y$. Dito de outra forma, não há certeza de que algum elemento de $\beta$ seja zero. Lewbel (2012) fornece um modo de identificação que dá embasamento a um modelo simples de estimador linear de dois estágios no caso em que nenhum elemento de $X$ é elemento excluído da equação $y$ e, portanto, não podendo ser usado como um instrumento para $S$. O método consiste em construir instrumentos válidos para $y$ explorando a informação contida na heteroscedasticidade de $\varepsilon_{2}$.

Assim, o estimador de Lewbel (2012) pode ser empregado da seguinte forma:

1) Estima-se $\hat{\alpha}$ por uma regressão de mínimos quadrados ordinários de $S$ em $X$, obtendo os resíduos $\hat{\varepsilon}_{2}=S-X^{\prime} \hat{\alpha}$

2) Seja $Z$ alguns ou todos os elementos de $X$, estima-se $\hat{\beta}$ e $\hat{\gamma}$ por uma regressão de dois estágios de $y$ em $X$ e $S$ usando como instrumentos $(Z-\bar{Z}) \hat{\varepsilon}_{2}$ e $X$, onde $\bar{Z}$ é a média amostral de $Z$.

Além da hipótese de exogeneidade para $X$, de modo que $E\left(X \varepsilon_{1}\right)=0$ e $E\left(X \varepsilon_{2}\right)=0$, é necessário ainda que, para aplicação deste estimador, os seguintes pressupostos sejam satisfeitos:

$$
\operatorname{Cov}\left(Z, \varepsilon_{1} \varepsilon_{2}\right)=0 \text { e } \operatorname{Cov}\left[Z, \varepsilon_{2}^{2}\right]=0
$$

O método Lewbel (2012) pode ser empregado para lidar com um possível viés na estimativa de $\beta_{\text {ATT }}$ causado pelas características não observáveis que influenciam o tratamento. Assim, parte-se da hipótese de que, se as correlações dos erros são causadas por fatores não observados, a identificação dos parâmetros estruturais pode ser obtida a partir de regressores não correlacionados com o produto dos erros heteroscedásticos. Dessa forma, o método consiste em explorar a heteroscedasticidade dos erros no primeiro estágio da regressão para gerar internamente instrumentos 
que possibilitem a identificação do modelo. Se U é uma variável omitida, que afeta a variável endógena de tratamento $\mathrm{S}$ e indiretamente y, é possível identificar o efeito causal de $\mathrm{S}$ em y, denotado por $\gamma$, através do Método de Momentos Generalizados (GMM).

Lewbel (2012) não assume explicitamente que $S$ é uma variável contínua, deixando ainda por demonstrar se as hipóteses de identificação podem ser satisfeitas no caso de $S$ não ser contínua. No caso que estamos analisando, temos que $S$ é uma variável que indica se o indivíduo está ou não inscrito no Programa Fies e, portanto, se enquadra na categoria de variável binária. Felizmente, Lewbel (2016) mostra que as hipóteses de identificação podem ser satisfeitas quando $S$ é uma variável binária e $S=X^{\prime} \alpha+\varepsilon_{2}$ é um modelo de probabilidade linear.

A presença de heteroscedasticidade, condição para a validade do método, pode ser analisada através do teste de Breusch-Pagan. Quanto maior o grau da heteroscedasticidade, maior será a correlação dos instrumentos gerados com as variáveis endógenas. Para testar a validade dos instrumentos, pode-se empregar o teste de Sargan ou teste J de Hansen. Se a validade é rejeitada, então o modelo está mal especificado ou os instrumentos não são válidos. Já o teste de KleibergenPaap Wald pode ser implementado para observar se os instrumentos internos gerados são relevantes para o tratamento.

\section{Dados e descrição das variáveis}

Os dados são do Exame Nacional de Desempenho de Estudantes (Enade), realizado pelo Instituto Nacional de Estudos e Pesquisas Educacionais Anísio Teixeira (Inep), com o objetivo de avaliar o desempenho dos estudantes concluintes dos cursos de graduação, em relação aos conteúdos programáticos, habilidades e competências adquiridas em sua formação. Além disso, são coletadas informações dos alunos, por meio de um questionário, com o objetivo de subsidiar a construção do perfil socioeconômico dos estudantes. O Enade abrange todo o território nacional e a periodicidade da avaliação é trienal para cada área do conhecimento (I - Saúde, Ciências Agrárias e áreas afins; II - Ciências Exatas, Licenciaturas e áreas afins; III - Ciências Sociais Aplicadas, Ciências Humanas e áreas afins).

A primeira aplicação do Enade ocorreu em 2004. Entre 2004 e 2008, o Exame foi realizado por Amostragem Probabilística Estratificada (seleção dos alunos) e, a partir de 2009, passou a ser censitário. As informações sobre o recebimento do Fies estão disponíveis a partir de 2007. Assim, nesse estudo são analisadas as informações dos estudantes dos cursos de graduação presencial em instituições privadas, nos anos de 2007 a 2017, contemplando todas as áreas avaliadas no Exame.

Conforme descrito na seção 3 deste texto, o histórico do Fies pode ser organizado em três fases principais, com base nas reformulações que ocorreram nos critérios de elegibilidade e nas condições de financiamento. Atualmente há também uma quarta fase, denominada de Novo Fies, após as reformulações de 2018. Nesse estudo, serão analisadas as duas primeiras fases da política, de 2000 a 2009 e de 2010 a 2014, de modo que as amostras de informações dos estudantes serão organizadas em dois grupos. O primeiro grupo é composto pelas informações dos alunos que ingressaram no ensino superior após 2000 e concluíram o curso até 2009, contemplando a primeira fase da política. Para o segundo grupo, serão selecionados os estudantes que ingressaram na educação superior em instituições privadas entre 2010 e 2014, quando estavam vigentes os critérios da segunda fase da 
política, que se caracteriza como a fase de grande flexibilização e expansão dos contratos. Devido ao reduzido número de estudantes que ingressaram na educação superior após as reformulações do Fies em 2015 e concluíram o curso até 2018, último resultado do Enade disponível, ainda não é possível avaliar precisamente as últimas fases da política.

O impacto do Fies será analisado por meio de duas variáveis de resultados, que são o tempo total e o atraso na conclusão do curso. O tempo de conclusão é o total de anos que o aluno esteve matriculado no curso, desde o ingresso até a conclusão. Porém, os cursos diferem quanto ao prazo mínimo estipulado para a integralização, de modo que um estudante pode levar menos tempo para concluir a educação superior simplesmente porque o prazo mínimo regulamentar para a conclusão do curso que está matriculado é menor. Diante disso, a variável atraso é definida como o número de anos que o estudante levou para concluir o curso além do prazo mínimo de integralização, de modo que os estudantes que concluíram o curso no tempo regulamentar ou antes, possuem atraso zero. Assim, além de levar em consideração os diferentes prazos de integralização dos cursos, essa variável capta o impacto do Fies especificamente sobre o atraso na conclusão do curso, para além do tempo regulamentar estipulado.

As médias dessas variáveis estão na Tabela 1. Observa-se que na primeira fase os alunos Fies levaram, em média, 4 meses a mais para completar o curso em relação aos alunos não Fies. Embora o tempo de conclusão de ambos os grupos tenha se reduzido na segunda fase, a diferença nas médias aumentou para 5 meses. $O$ atraso na conclusão do curso também reduziu para ambos os grupos na segunda fase, porém a diferença entre as médias não foi significativa.

Tabela 1

Médias das variáveis de resultado

\begin{tabular}{lcccccc}
\hline $\begin{array}{l}\text { Variáveis de } \\
\text { resultado }\end{array}$ & Fies & N.Fies & Dif. & Fies & N.Fies & Dif. \\
\hline \multirow{2}{*}{ Tempo de conclusão } & 4,713 & 4,310 & $0,403^{*} * *$ & 4,422 & 3,954 & $0,469^{* * * *}$ \\
& $(0,010)$ & $(0,003)$ & $(0,011)$ & $(0,002)$ & $(0,002)$ & $(0,003)$ \\
Atraso & 0,560 & 0,479 & $0,081^{* * *}$ & 0,280 & 0,257 & 0,023 \\
& $(0,008)$ & $(0,002)$ & $(0,008)$ & $(0,001)$ & $0,001)$ & $(0,015)$ \\
Observações & 16.051 & 232.860 & & 211.335 & 605.342 & \\
\hline
\end{tabular}

Fonte: INEP 2007-2017 (Enade, Censo da Educação Superior e IGC)

Nota: *** denota significância da diferença de médias ao nível de 1\%. Erro-padrão entre parênteses.

O Quadro 1 apresenta a descrição das variáveis utilizadas para parear os grupos de controle e tratamento e, também, como controles nas estimativas do ATT. As estatísticas descritivas dessas variáveis, para ambos os grupos nas duas fases da política, estão nos Apêndices 1, 2, 3 e 4 . As variáveis idade, homem e cor referem-se às características do indivíduo. Desjardins et al. (2002) argumenta que os estudantes mais velhos têm maiores custos de oportunidade e, por isso, podem levar mais tempo para concluir o curso. É possível também que o tempo de conclusão do ensino superior seja diferente entre os grupos raciais, uma vez que as oportunidades de emprego e as taxas de retorno da educação sobre os salários divergem entre as categorias de cor, o que, por sua vez, pode interferir no processo de decisão de alocação do tempo entre trabalhar e estudar (Chadarevian, 2011). 
Da mesma forma, a escolaridade dos pais também pode estar associada ao tempo de conclusão do curso, uma vez que vários estudos apontam que essa variável afeta os resultados escolares dos filhos e, consequentemente, as oportunidades no mercado de trabalho (Becker, 2018; Reis; Ramos, 2011).

Assim como os indivíduos mais velhos, indivíduos casados e que moram com o cônjuge ou filhos podem ter maiores custos de oportunidade de abdicar da renda do trabalho, em razão das obrigações familiares (Rocha, 2016). Os indivíduos que trabalham possuem menos tempo para se dedicar aos estudos e, dessa forma, é possível que levem um tempo maior para concluir o curso. Nos Apêndices 1 e 2 observa-se que, na primeira fase, 70\% dos estudantes Fies e 75\% dos não Fies trabalhavam. Na segunda fase, essa proporção reduziu-se para $59 \%$ e $68 \%$, respectivamente.

A renda da família é um importante determinante da demanda por educação. Kane (2003) aponta evidências de uma forte correlação positiva da renda familiar sobre as taxas de matrícula, permanência e conclusão do ensino superior. As variáveis de rendimento da família e situação financeira buscam captar essa relação. A renda familiar também é uma variável importante para determinar a probabilidade de participação no Fies, uma vez que o critério vigente entre 2010 e 2014 é que essa renda deveria ser de até 20 salários-mínimos e o comprometimento da renda familiar mensal bruta per capita deveria ser superior a $20 \%$.

Quadro 1

Definição das variáveis

\begin{tabular}{|c|c|}
\hline Controles & Descrição \\
\hline Idade & Idade (anos) \\
\hline Homem & Var. Bin. =1 se o indivíduo é homem e 0 c.c. \\
\hline Cor 0 (branco) & Indivíduo branco (base). Var. categ. $=0$ \\
\hline Cor 1 (preto) & Indivíduo preto. Var. categ. $=1$ \\
\hline Cor 2 (pardo) & Indivíduo pardo. Var. categ. $=2$ \\
\hline Cor 3 (amar.) & Indivíduo amarelo. Var. categ. $=3$ \\
\hline Cor 4 (indig.) & Indivíduo indígena. Var. categ. $=4$ \\
\hline Escpai 0 & Pai nunca estudou oи não completou o Ensino Fundamental (base). Var. categ. $=0$ \\
\hline Escpai $1(\mathrm{EF})$ & Pai com Ensino Fundamental. Var categ. $=1$ \\
\hline Escpai 2 (EM) & Pai com Ensino Médio. Var categ.=2 \\
\hline Escpai 3 (ES) & Pai com Ensino Superior. Var categ. $=3$ \\
\hline Escmãe 0 & Mãe nunca estudou ou não completou o Ensino Fundamental (base). Var. categ. $=0$ \\
\hline Escmãe $1(\mathrm{EF})$ & Mãe com Ensino Fundamental. Var categ.=1 \\
\hline Escmãe 2 (EM) & Mãe com Ensino Médio. Var categ.=2 \\
\hline Escmãe 3 (ES) & Mãe com Ensino Superior. Var categ.=3 \\
\hline Estcivil 0 & Indivíduo solteiro (base). Var. categ. $=0$ \\
\hline Estcivil 1 (cas.) & Indivíduo casado. Var. categ. $=1$ \\
\hline Estcivil 2 (sep.) & Indivíduo separado/viúvo. Var. categ. $=2$ \\
\hline
\end{tabular}

Continua... 
Políticas de financiamento estudantil: análise de impacto do Fies no tempo de conclusão do ensino superior

Quadro 1 - Continuação

\begin{tabular}{|c|c|}
\hline Controles & Descrição \\
\hline Cmora. 0 & Indivíduo mora sozinho (base). Var. categ. $=0$ \\
\hline Cmora. 1 (pais) & Indivíduo mora com pais e/ou parentes. Var. categ. $=1$ \\
\hline Cmora. 2 (con.) & Indivíduo mora com cônjuge e/ou filhos. Var. categ. $=2$ \\
\hline Cmora. 3 (rep.) & Indivíduo mora em república / alojamento / outros Var. categ. $=3$ \\
\hline Trabalha & Var. Bin. $=1$ se o indivíduo trabalha e 0 c.c. \\
\hline$R F O$ & Renda Familiar até 3 salário-mínimo (base). Var. categ. $=0$ \\
\hline RF 1 (3 a 10) & Renda Familiar de 3 a 10 salários-mínimos. Var. categ. $=1$ \\
\hline RF 2 (10 a 30) & Renda Familiar de 10 a 30 salários-mínimos. Var. categ. $=2$ \\
\hline Sit. Fin. 0 & $\begin{array}{l}\text { Não tem renda e os gastos são financiados por programas governamentais, pela } \\
\text { família, ou por outras pessoas (base). Var. categ. }=0\end{array}$ \\
\hline Sit. Fin. 1 (aj.) & Tem renda, mas recebe ajuda da família ou de outras pessoas. Var. categ. $=1$ \\
\hline Sit. Fin. 2 (naj.) & Tem renda e não precisa de ajuda para financiar os gastos. Var. categ. $=2$ \\
\hline Sit. Fin. 3 (ct.) & Tem renda e contribui/ é responsável com o sustento da família. Var. categ.=3 \\
\hline EM Esc. Pub. & Var. Bin. $=1$ se realizou todo ou a maior parte do EM em escola pública e 0 c.c. \\
\hline M.EMO & Modalidade: Ensino médio tradicional (base). Var. categ. $=0$ \\
\hline M.EM1(Profis.) & Profissionalizante (técnico / magistério). Var. categ. $=1$ \\
\hline M. EM2(EJA) & Educação de Jovens e Adultos (EJA) e/ou Supletivo ou outra modalid. Var. categ.=2 \\
\hline Noturno & Var. Bin. $=1$ se estuda a noite e 0 c.c. \\
\hline TIESO & Tipo da Instituição: Universidade (base). Var. categ. $=0$ \\
\hline T IES1 (CU) & Centro Universitário. Var. categ. $=1$ \\
\hline T IES2 (Facul.) & Faculdade. Var. categ. $=2$ \\
\hline Área conh. 0 & Área do conhecimento: Saúde, Ciências Agrárias e áreas afins. (base). Var. categ. $=0$ \\
\hline Área conh. 1 & Ciências Exatas, Licenciaturas e áreas afins. Var. categ. $=1$ \\
\hline Área conh. 2 & Ciências Sociais Aplicadas, Ciências Humanas e áreas afins. Var. categ. $=2$ \\
\hline IGC & Índice geral de cursos: disponibilizado pelo INEP \\
\hline Reg. 0 & Norte (base). Var. categ. $=0$ \\
\hline Reg. 1 & Nordeste. Var. categ. $=1$ \\
\hline Reg. 2 & Sudeste. Var. categ. $=2$ \\
\hline Reg. 3 & Sul. Var. categ. $=3$ \\
\hline Reg. 4 & Centro-Oeste. Var. categ. $=4$ \\
\hline
\end{tabular}

Fonte: INEP (Enade, Censo da Educação Superior e IGC).

Nos Apêndices 1 e 2 observa-se que, na primeira fase, a maioria dos alunos tinha renda familiar de 3 a 10 salários-mínimos, uma vez que a proporção nessa faixa de renda é pouco mais de $50 \%$, tanto para alunos Fies como não Fies. Na segunda fase, a proporção de alunos Fies nessa faixa reduziu-se para $41 \%$ e a maior proporção, $56 \%$, concentrou-se na faixa de renda familiar de até 3 salários mínimos. Isso pode ser um indicativo de que o critério de elegibilidade com base na renda que foi implementado na segunda fase, conforme descrito no Quadro 2 desse texto, contribuiu para a maior focalização da política nos estudantes de baixa renda. 
As variáveis do setor e da modalidade do ensino médio buscam identificar a qualidade da base escolar dos estudantes uma vez que, geralmente, os estudantes de escolas públicas e, principalmente, aqueles concluíram o ensino médio por meio do EJA ou supletivo apresentam piores resultados, o que pode aumentar o tempo de conclusão do curso (Oliveira et al, 2013).

Os estudantes que estudam à noite, geralmente, levam mais tempo para concluir o curso. As taxas de conclusão também podem divergir entre as diferentes áreas do conhecimento, bem como o tipo de instituição. Por fim, utiliza-se uma variável categórica para diferenciar as 5 regiões do país.

\section{Resultados}

A seguir, na seção 6.1, faremos uma descrição dos resultados do modelo probit, que estima a probabilidade de participação no Fies e que serve de base para aplicação da metodologia de score de propensão. Foram incluídas no modelo todas as características observadas que podem afetar tanto o tratamento (Fies) quanto os resultados analisados, que são o tempo total e o atraso na conclusão do curso. Na seção 6.2 apresentaremos os resultados da avaliação de impacto do Fies sobre o tempo e atraso na conclusão do curso.

\subsection{Probabilidade de participação no Fies e pareamento dos grupos controle e tratamento}

Na Tabela 2 estão representados os resultados do modelo probit, que estima a probabilidade de participação no Fies. Ao final da Tabela estão as medidas que avaliam o poder preditivo do modelo ao comparar a correspondência dos valores efetivos e previstos da variável dependente.

O percentual de valores corretamente especificados foi $67,22 \%$ na primeira fase do Fies e $66,73 \%$ na segunda fase. A medida de sensibilidade refere-se à proporção das observações Fies=1 que foram corretamente especificadas, correspondendo a $57,17 \%$ na primeira fase e $53,37 \%$ na segunda fase. Já a medida de especificidade refere-se à proporção das observações Fies $=0$ que foram corretamente especificadas, correspondendo a $67,92 \%$ na primeira fase e $71,40 \%$ na segunda fase.

Tabela 2

Modelo Probit para a probabilidade de participação no Fies

\begin{tabular}{|c|c|c|c|c|}
\hline & $1^{\mathrm{a}}$. Fase & Efeito Marginal & $2^{\mathrm{a}}$. Fase & Efeito Marginal \\
\hline Idade & $\begin{array}{c}0,002 * * * \\
(0,001)\end{array}$ & 0,000 & $\begin{array}{c}0,007 * * * \\
(0,000)\end{array}$ & 0,002 \\
\hline Homem & $\begin{array}{c}0,042 * * * \\
(0,008)\end{array}$ & 0,005 & $\begin{array}{c}0,027 * * * \\
(0,003)\end{array}$ & 0,008 \\
\hline \multicolumn{5}{|l|}{ Cor O (branco) } \\
\hline Cor 1 (preto) & $\begin{array}{c}0,104 * * * \\
(0,016)\end{array}$ & 0,013 & $\begin{array}{c}0,046 * * * \\
(0,006)\end{array}$ & 0,015 \\
\hline Cor 2 (pardo) & $\begin{array}{c}0,048 * * * \\
(0,010)\end{array}$ & 0,006 & $\begin{array}{c}0,059 * * * \\
(0,004)\end{array}$ & 0,019 \\
\hline Cor 3 (amar.) & $\begin{array}{l}-0,045 \\
(0,033)\end{array}$ & $-0,005$ & $\begin{array}{c}0,023 * * \\
(0,011)\end{array}$ & 0,007 \\
\hline Cor 4 (indig.) & $\begin{array}{c}-0,014 \\
(0,044)\end{array}$ & $-0,002$ & $\begin{array}{c}-0,104 * * * \\
(0,022)\end{array}$ & $-0,031$ \\
\hline
\end{tabular}

Continua... 
Tabela 2 - Continuação

\begin{tabular}{|c|c|c|c|c|}
\hline & $1^{\mathrm{a}}$. Fase & Efeito Marginal & $2^{\mathrm{a}}$. Fase & Efeito Marginal \\
\hline \multicolumn{5}{|l|}{ Escpai $O(N . E F)$} \\
\hline Escpai $1(\mathrm{EF})$ & $\begin{array}{l}-0,007 \\
(0,013)\end{array}$ & $-0,001$ & $\begin{array}{c}0,012 * * \\
(0,005)\end{array}$ & 0,004 \\
\hline Escpai 2 (EM) & $\begin{array}{c}-0,026^{* *} \\
(0,012)\end{array}$ & $-0,003$ & $\begin{array}{c}0,014 * * * \\
(0,004)\end{array}$ & 0,004 \\
\hline Escpai 3 (ES) & $\begin{array}{c}-0,109 * * * \\
(0,016)\end{array}$ & $-0,012$ & $\begin{array}{c}-0,028 * * * \\
(0,006)\end{array}$ & $-0,009$ \\
\hline \multicolumn{5}{|l|}{ Escmãe O (N. EF) } \\
\hline Escmãe 1 (EF) & $\begin{array}{c}0,013 \\
(0,013)\end{array}$ & 0,001 & $\begin{array}{c}0,028 * * * \\
(0,005)\end{array}$ & 0,009 \\
\hline Escmãe 2 (EM) & $\begin{array}{c}0,050 * * * \\
(0,012)\end{array}$ & 0,006 & $\begin{array}{c}0,037 * * * \\
(0,005)\end{array}$ & 0,012 \\
\hline Escmãe 3 (ES) & $\begin{array}{c}0,054 * * * \\
(0,015)\end{array}$ & 0,006 & $\begin{array}{c}0,066 * * * \\
(0,006)\end{array}$ & 0,021 \\
\hline \multicolumn{5}{|l|}{ Estcivil O (solteiro) } \\
\hline Estcivil 1 (cas.) & $\begin{array}{c}-0,079 * * * \\
(0,013)\end{array}$ & $-0,009$ & $\begin{array}{c}-0,047 * * * \\
(0,006)\end{array}$ & $-0,014$ \\
\hline Estcivil 2 (sep.) & $\begin{array}{c}0,022 \\
(0,018)\end{array}$ & 0,002 & $\begin{array}{c}0,035 * * * \\
(0,007)\end{array}$ & 0,011 \\
\hline \multicolumn{5}{|c|}{ Cmora. $O$ (sozinho) } \\
\hline Cmora. 1 (pais) & $\begin{array}{c}0,044 \\
(0,029)\end{array}$ & 0,005 & $\begin{array}{c}-0,089 * * * \\
(0,006)\end{array}$ & $-0,028$ \\
\hline Cmora. 2 (conj) & $\begin{array}{c}0,069 * * \\
(0,030)\end{array}$ & 0,008 & $\begin{array}{c}-0,049 * * * \\
(0,008)\end{array}$ & $-0,015$ \\
\hline Cmora. 3 (rep.) & $\begin{array}{c}0,152 * * * \\
(0,032)\end{array}$ & 0,018 & $\begin{array}{c}0,038 * * * \\
(0,009)\end{array}$ & 0,012 \\
\hline Trabalha & $\begin{array}{c}-0,087 * * * \\
(0,013)\end{array}$ & $-0,010$ & $\begin{array}{c}-0,115^{* * *} \\
(0,004)\end{array}$ & $-0,036$ \\
\hline RF O (até 3) & & & & \\
\hline RF 1 (3 a 10) & $\begin{array}{c}-0,119 * * * \\
(0,009)\end{array}$ & $-0,014$ & $\begin{array}{c}-0,269 * * * \\
(0,003)\end{array}$ & $-0,083$ \\
\hline RF 2 (10 a 30) & $\begin{array}{c}-0,463 * * * \\
(0,015)\end{array}$ & $-0,042$ & $\begin{array}{c}-0,782 * * * \\
(0,008)\end{array}$ & $-0,184$ \\
\hline \multicolumn{5}{|c|}{ Sit. Fin. $O($ sem renda $)$} \\
\hline Sit. Fin. 1 (aj.) & $\begin{array}{c}0,012 \\
(0,014)\end{array}$ & 0,001 & $\begin{array}{c}-0,103 * * * \\
(0,005)\end{array}$ & $-0,032$ \\
\hline Sit. Fin. 2 (naj.) & $\begin{array}{c}-0,033 * * \\
(0,016)\end{array}$ & $-0,004$ & $\begin{array}{c}-0,301 * * * \\
(0,006)\end{array}$ & $-0,086$ \\
\hline Sit. Fin. 3 (cont.) & $\begin{array}{c}-0,044 * * * \\
(0,017)\end{array}$ & $-0,005$ & $\begin{array}{c}0,021 * * * \\
(0,005)\end{array}$ & 0,007 \\
\hline EM esc. Pub. & $\begin{array}{c}0,118 * * * \\
(0,010)\end{array}$ & 0,013 & $\begin{array}{c}0,113 * * * \\
(0,004)\end{array}$ & 0,035 \\
\hline \multicolumn{5}{|c|}{ M.EM O (EM regular) } \\
\hline M.EM1(Profis.) & $\begin{array}{c}0,041 * * * \\
(0,011)\end{array}$ & 0,005 & $\begin{array}{c}-0,167 * * * \\
(0,005)\end{array}$ & $-0,049$ \\
\hline
\end{tabular}

Continua... 
Tabela 2 - Continuação

\begin{tabular}{|c|c|c|c|c|}
\hline & $1^{\mathrm{a}}$. Fase & Efeito Marginal & $2^{\mathrm{a}}$. Fase & Efeito Marginal \\
\hline M. EM2(EJA) & $\begin{array}{c}0,037 * * \\
(0,018)\end{array}$ & 0,004 & $\begin{array}{c}0,017 * * * \\
(0,006)\end{array}$ & 0,005 \\
\hline Noturno & $\begin{array}{c}-0,040 * * * \\
(0,011)\end{array}$ & $-0,005$ & $\begin{array}{c}-0,015 * * * \\
(0,004)\end{array}$ & $-0,005$ \\
\hline \multicolumn{5}{|l|}{ T IESO (Universidade) } \\
\hline T IES 1 (CU) & $\begin{array}{c}0,130 * * * \\
(0,011)\end{array}$ & 0,016 & $\begin{array}{c}0,257 * * * \\
(0,005)\end{array}$ & 0,084 \\
\hline T IES 2 (Facul.) & $\begin{array}{c}0,126 * * * \\
(0,010)\end{array}$ & 0,015 & $\begin{array}{c}0,215 * * * \\
(0,004)\end{array}$ & 0,067 \\
\hline Área conh. 0 & & & & \\
\hline Área conh. 1 & $\begin{array}{c}-0,339 * * * \\
(0,014)\end{array}$ & $-0,033$ & $\begin{array}{c}-0,086^{* * *} \\
(0,004)\end{array}$ & $-0,027$ \\
\hline Área conh. 2 & $\begin{array}{c}-0,422 * * * \\
(0,015)\end{array}$ & $-0,053$ & $\begin{array}{c}-0,419 * * * \\
(0,004)\end{array}$ & $-0,129$ \\
\hline IGC & $\begin{array}{c}0,091 * * * \\
(0,009)\end{array}$ & 0,010 & $\begin{array}{c}0,129 * * * \\
(0,003)\end{array}$ & 0,040 \\
\hline \multicolumn{5}{|l|}{ Reg. O Norte } \\
\hline Reg. 1 Nordeste & $\begin{array}{c}0,230 * * * \\
(0,022)\end{array}$ & 0,030 & $\begin{array}{c}0,230 * * * \\
(0,007)\end{array}$ & 0,075 \\
\hline Reg. 2 Sudeste & $\begin{array}{c}-0,307 * * * \\
(0,021)\end{array}$ & $-0,036$ & $\begin{array}{c}-0,032 * * * \\
(0,007)\end{array}$ & $-0,010$ \\
\hline Reg. 3 Sul & $\begin{array}{l}-0,039 * \\
(0,022)\end{array}$ & $-0,004$ & $\begin{array}{c}0,066^{* * *} \\
(0,008)\end{array}$ & 0,021 \\
\hline Reg. 4 Centro-Oeste & $\begin{array}{c}-0,166^{* * * *} \\
(0,024)\end{array}$ & $-0,017$ & $\begin{array}{c}0,168 * * * \\
(0,008)\end{array}$ & 0,055 \\
\hline Const. & $\begin{array}{c}-1,395^{* * *} \\
(0,050)\end{array}$ & & $\begin{array}{c}-0,984 * * * \\
(0,018)\end{array}$ & \\
\hline Observações & 248.911 & & 816.677 & \\
\hline Log pseudolikelihood & $-56516,177$ & & $-433153,14$ & \\
\hline Pseudo $\mathrm{R}^{2}$ & 0,0505 & & 0,0724 & \\
\hline Sensibilidade & $57,17 \%$ & & $53,37 \%$ & \\
\hline Especificidade & $67,92 \%$ & & $71,40 \%$ & \\
\hline Classificação & $67,22 \%$ & & $66,73 \%$ & \\
\hline
\end{tabular}

Nota: $* * *, * *, *$ denotam significância ao nível de 1\%,5\% e 10\%. Erro-padrão entre parênteses.

Fonte: INEP 2007-2017 (Enade, Censo da Educação Superior e IGC).

Os coeficientes estimados para a idade do indivíduo foram positivos e significativos em ambas as fases, porém os efeitos marginais foram próximos a zero. Homens tem maior chance de participar da política, assim como indivíduos da cor preta e parda, em relação aos indivíduos da cor branca. $\mathrm{O}$ coeficiente dos indivíduos amarelos foi significativo apenas na $2^{\mathrm{a}}$. fase, assim como o dos indígenas, porém esses apresentaram menor probabilidade de receber o Fies em relação aos brancos.

Na primeira fase do Fies, os jovens cujos pais têm ensino médio ou superior apresentaram menor probabilidade de participar do programa em relação àqueles cujos pais não completaram o 
ensino fundamental. Já na segunda fase, os estudantes cujos pais têm ensino fundamental ou médio apresentaram maior probabilidade, enquanto aqueles cujos pais têm ensino superior apresentaram menor probabilidade. No caso da escolaridade da mãe, os coeficientes significativos foram todos positivos, o que indica que uma maior escolaridade da mãe está associada à maior probabilidade de participação no Fies. Na segunda fase, o fato de a mãe ter ensino superior aumentou a participação no Fies em 0,021.

Os jovens que buscam crédito para financiar os estudos, geralmente, são aqueles que não dispõem de recursos próprios ou familiares, o que poderia explicar os coeficientes negativos da variável de escolaridade do pai, uma vez que essa variável pode estar associada a maior vulnerabilidade socioeconômica da família. Por outro lado, muitos estudos apontam que a escolaridade dos pais, principalmente da mãe, é um determinante importante do comportamento do jovem e está associada a vários resultados da vida do indivíduo, como proficiência e inserção no mercado de trabalho (Becker, 2018; Reis; Ramos, 2011). Isso poderia explicar os resultados positivos da variável de escolaridade da mãe, uma vez que pode influenciar o engajamento do jovem em buscar o financiamento para completar os estudos.

Indivíduos casados apresentaram menor probabilidade de receber o Fies em relação aos indivíduos solteiros em ambas as fases da política. Já os indivíduos separados ou viúvos apresentaram maior probabilidade na $2^{\text {a }}$. fase. Indivíduos que moravam com os pais apresentaram menor probabilidade de receber o Fies, em relação aos estudantes que moravam sozinhos na $2^{\mathrm{a}}$. fase. $\mathrm{O}$ fato de morar com o cônjuge aumentou a participação no Fies em 0,008 na $1^{\mathrm{a}}$. fase e diminuiu em $-0,015$ na $2^{\text {a }}$. fase. Já os estudantes que moravam em república apresentaram maior probabilidade em ambas as fases, o que pode estar associado à possibilidade de que os estudantes que moram em república, provavelmente, apresentam restrições orçamentárias maiores em relação àqueles que moram sozinhos e, portanto, maior chance de recorrer ao Fies.

Os estudantes que trabalham apresentaram menor probabilidade de receber o Fies em ambas as fases da política. Na primeira fase, comparado aos estudantes com renda familiar inferior a 3 salários-mínimos (sm), aqueles com renda familiar entre 3 e $10 \mathrm{sm}$ tiveram a probabilidade de participação no Fies reduzida em -0,014 e aqueles com renda familiar entre 10 e $30 \mathrm{sm}$ apresentaram $-0,042$ menor probabilidade de participação. Já na $2^{\mathrm{a}}$. fase, esses valores são de $-0,083$ e $-0,184$, respectivamente. Esse resultado pode ser mais uma evidência em favor da hipótese de que o critério de elegibilidade com base na renda que foi implementado na segunda fase contribuiu para a maior focalização da política nos estudantes de baixa renda. Conforme descrito na seção anterior, $56 \%$ dos alunos Fies na segunda fase da política estavam na faixa de renda familiar de até 3 salários mínimos. Na primeira fase eram $39 \%$ nessa faixa.

Com relação à situação financeira, na primeira fase, os estudantes que possuíam renda e que não recebiam ajuda da família ou que contribuíam com o sustento dessa apresentavam menor probabilidade de receber o Fies em relação àqueles que não possuíam renda. Já na $2^{\mathrm{a}}$. fase, aqueles que contribuíam para o sustento da família aumentaram a probabilidade de participação no programa em 0,007 .

Estudantes que realizaram o ensino médio em escola pública apresentaram 0,013 maior probabilidade de receber o Fies na primeira fase e 0,035 na segunda fase. Estudantes que concluíram 
o ensino médio por meio do EJA ou supletivo também apresentaram maior chance de participar da política, em relação àqueles que concluíram por meio do sistema regular. Já aqueles que realizaram ensino médio profissionalizante apresentaram 0,005 maior probabilidade de participação na primeira fase e $-0,049$ menor probabilidade na $2^{\mathrm{a}}$. fase.

Alunos de cursos noturnos apresentaram menor probabilidade de participar do Fies, assim como aqueles matriculados em universidades, em relação aos matriculados em centros universitários e faculdades. Alunos das áreas exatas, licenciaturas, sociais aplicadas, e áreas afins apresentam menor chance de receber o Fies em relação aos alunos matriculados em cursos da área da saúde, ciências agrárias e áreas afins.

Um maior IGC aumenta a probabilidade de o aluno participar do Fies. Na primeira fase, esse aumento foi de 0,01 e na segunda fase foi de 0,04 , o que pode estar relacionado ao fato de que na $2^{\mathrm{a}}$. fase passou-se a exigir dos cursos conceito de, no mínimo, 3 para participação no Fies, com o intuito de alocar os recursos públicos para a formação dos alunos em cursos com maior qualidade.

$\mathrm{Na}$ primeira fase, com exceção da região Nordeste, os estudantes das demais regiões apresentavam menor probabilidade de participar do Fies em relação aos estudantes da região Norte. Já na segunda fase, os estudantes das regiões Sul e Centro-Oeste passaram a apresentar maior probabilidade.

Os resultados do modelo probit servem de base para a aplicação da metodologia de pareamento por score de propensão. Foram utilizados os algoritmos de pareamento por 1 vizinho mais próximo - $\mathrm{Nn}(1), 5$ vizinhos mais próximos - $\mathrm{Nn}(5)$ e kernel. Não houve observações fora do suporte comum. Para avaliar a qualidade do pareamento aplicamos os testes propostos por Dehejia e Wahba (2002), cujos resultados estão na Tabela 3. Os resultados do Pseudo- $\mathrm{R}^{2}$ reduziram-se após o pareamento para valores bem próximos a zero em todos os algoritmos adotados para parear a amostra, o que sugere que o modelo após o pareamento tem menor poder para explicar a condição de tratamento. Observa-se também a redução do viés após o pareamento, dado pela diferença de média e de mediana entre as características observáveis do grupo controle e tratamento. Já o teste da Razão de Verossimilhança $(L R)$ aponta que os regressores foram conjuntamente não significativos apenas nas amostras da $1^{\text {a }}$. fase do Fies pareadas por vizinhos mais próximos.

Tabela 3

Testes da qualidade do Pareamento

\begin{tabular}{lccccc}
\hline Amostra & Pseudo-R & LR $\chi^{2}$ & $p>\chi^{2}$ & Viés médio & Viés Mediano \\
\hline $1^{\text {a }}$. Fase & \multicolumn{5}{c}{} \\
\hline Não Pareado & 0,051 & 6013,6 & 0,000 & 8,6 & 5,4 \\
Nn(1) & 0,001 & 33,00 & 0,612 & 1,0 & 0,9 \\
Nn(5) & 0,000 & 8,81 & 1,000 & 0,5 & 0,4 \\
Kernel & 0,007 & 309,85 & 0,000 & 2,5 & 1,5 \\
\hline $2^{\text {a }}$. Fase & & & & 7,2 \\
\hline Não Pareado & 0,072 & 67598,08 & 0,000 & 10,2 & 0,8 \\
Nn(1) & 0,001 & 632,27 & 0,000 & 1,1 & 0,7 \\
Nn(5) & 0,001 & 338,28 & 0,000 & 0,8 & 2,1 \\
Kernel & 0,008 & 874,05 & 0,000 & 3,4 & \\
\hline
\end{tabular}

Fonte: INEP 2007-2017 (Enade, Censo da Educação Superior e IGC). 
Analisamos também as diferenças nas médias das covariadas dos grupos controle e tratamento, antes e depois do pareamento. Os resultados da amostra pareada pelos 5 vizinhos mais próximos $^{2}$, que apresentou os melhores resultados nos testes de Dehejia e Wahba (2002), estão nos Apêndices 1 e 2. Observa-se que o score de propensão contribuiu significativamente para reduzir a diferença nas características observáveis dos alunos nos grupos controle e tratamento. Porém, algumas variáveis não estão balanceadas, isto é, não são estatisticamente iguais para os grupos, principalmente na $2^{\mathrm{a}}$. fase do Fies. Assim, com o intuito de alcançar um nível de balanceamento desejável para distribuições das variáveis nos grupos de tratamento e controle, aplicamos também o método de pareamento por entropia, cujos resultados estão nos Apêndices 3 e 4.

\subsection{Impacto do Fies sobre o tempo e atraso na conclusão do curso}

A Tabela 4 apresenta os resultados do efeito médio do tratamento (ATT) no tempo total e o atraso na conclusão do curso, obtido por meio dos métodos de pareamento por escore de propensão (PSM) e por Entropia. A Tabela também apresenta os resultados das estimativas do modelo estimado pelo método de Lewbel (2012), na tentativa de lidar com o possível viés das características não observáveis que influenciam a decisão individual de solicitar o Fies. Os resultados do teste Breusch e Pagan confirmam heterocedasticia dos erros, condição para a validade do método $\left(\chi^{2}=5026,76\right.$ para a $1^{\mathrm{a}}$. fase; $\chi^{2}=4100,00$ para a $2^{\mathrm{a}}$. fase). O teste de Kleibergen-Paap Wald permitiu rejeitar a $1 \%$ a hipótese nula de que os instrumentos são fracos, sugerindo que os instrumentos internos gerados são relevantes para o tratamento $\left(\mathrm{F}=236,81\right.$ para a $1^{\mathrm{a}}$. fase; $\mathrm{F}=772,40$ para a $2^{\mathrm{a}}$. fase). Os resultados do teste de sobreidentificação das restrições $\mathrm{J}$ de Hansen, nas últimas linhas da Tabela 2, indicaram a falha na rejeição da hipótese nula a 5\%, o que é uma evidência de que os instrumentos são válidos. Também são reportados os coeficientes estimados pelo método de mínimos quadrados ordinários (MQO) com a finalidade de comparar os resultados.

Tabela 4

Estimativas do Efeito de Tratamento Médio (Fies)

\begin{tabular}{|c|c|c|c|c|}
\hline \multirow{2}{*}{ ATT - Fies } & \multicolumn{2}{|c|}{ Tempo de conclusão } & \multicolumn{2}{|c|}{ Atraso } \\
\hline & $1^{\mathrm{a}}$. Fase & $2^{a}$. Fase & $1^{\mathrm{a}}$. Fase & $2^{\mathrm{a}}$. Fase \\
\hline \multicolumn{5}{|l|}{ MQO } \\
\hline & $0,411 * * *$ & $0,374 * * *$ & $0,083 * * *$ & $0,032 * * *$ \\
\hline & $(0,010)$ & $(0,003)$ & $(0,008)$ & $(0,001)$ \\
\hline \multicolumn{5}{|l|}{ PSM } \\
\hline \multirow{2}{*}{$\mathrm{Nn}(1)$} & $0,386 * * *$ & $0,418 * * *$ & $0,068 * * *$ & 0,052 \\
\hline & $(0,015)$ & $(0,005)$ & $(0,011)$ & $(0,062)$ \\
\hline \multirow{2}{*}{$\mathrm{Nn}(5)$} & $0,412 * * *$ & $0,360 * * *$ & $0,082 * * *$ & 0,061 \\
\hline & $(0,012)$ & $(0,003)$ & $(0,009)$ & $(0,062)$ \\
\hline \multirow{2}{*}{ Kernel } & $0,366 * * *$ & $0,419 * * *$ & $0,084 * * *$ & $0,236 * * *$ \\
\hline & $(0,006)$ & $(0,002)$ & $(0,005)$ & $(0,003)$ \\
\hline
\end{tabular}

(2) Os resultados de diferença médias dos pareamentos obtidos pelos demais algoritmos podem ser obtidos com os autores. 
Kalinca Léia Becker, Mário Jorge Cardoso de Mendonça

Tabela 4 - Continuação

\begin{tabular}{lcccc}
\hline \multirow{2}{*}{ ATT - Fies } & \multicolumn{2}{c}{ Tempo de conclusão } & \multicolumn{2}{c}{ Atraso } \\
\cline { 2 - 5 } P. Entropia & $1^{\text {a }}$. Fase & $2^{\text {a }}$. Fase & $1^{\text {a }}$. Fase & $2^{\text {a }}$. Fase \\
\hline & $0,713^{* * *}$ & $2,422^{* *}$ & 0,560 & $1,772^{* * *}$ \\
& $(0,012)$ & $(1,154)$ & $(0,792)$ & $(0,001)$ \\
\hline Lewbel & & & \\
\hline & $0,318^{* * *}$ & $0,126^{* * *}$ & $0,067 * * *$ & $0,050^{* * *}$ \\
& $(0,019)$ & $(0,008)$ & $(0,015)$ & $(0,006)$ \\
\hline Hansen $\mathrm{J}\left(\chi^{2}\right)$ & 47,838 & 37,676 & 36,246 & 43,730 \\
$p$-valor & 0,0726 & 0,3478 & 0,4103 & 0,1478 \\
\hline
\end{tabular}

Fonte: INEP 2007-2017 (Enade, Censo da Educação Superior e IGC)

Nota: ***,**, * denotam significância ao nível de $1 \%, 5 \%$ e $10 \%$. Desvio-padrão robusto entre parênteses, com bootstrap 1000 replicações.

Os resultados indicaram que a participação no Fies aumentou o tempo de conclusão do curso de graduação. Em ambas as fases analisadas, o impacto estimado por PSM foi em torno de 4 meses. Os resultados das estimativas do método de Lewbel (2012) evidenciaram uma possível superestimação do efeito médio do tratamento quando não são consideradas as características não observadas dos alunos, uma vez que o efeito do Fies sobre o tempo de conclusão do curso foi de 3 meses na primeira fase e 1 mês na segunda fase. Já os resultados obtidos por meio do pareamento por Entropia foram de 7 meses na primeira fase e 2 anos e quatro meses na segunda fase. Esses resultados são discrepantes em relação aos resultados obtidos pelos demais métodos, principalmente na segunda fase, o que também ocorre para a variável atraso.

Os resultados da variável atraso também indicaram um impacto positivo do Fies, porém em menor intensidade, uma vez que a participação na primeira fase do programa aumentou em menos de um mês o atraso na conclusão do curso, além do tempo mínimo. O impacto estimado pelos diferentes métodos foi em torno de 0,07 e 0,08. Já na segunda fase as estimativas do efeito médio do tratamento por PSM foram significativas apenas para o pareamento obtido pelo algoritmo de kernel. Porém, lembramos que os resultados dos testes de Dehejia e Wahba (2002), discutidos na seção anterior, não indicaram a qualidade do balanceamento dos grupos. Os resultados do método de Lewbel (2012) indicaram um efeito do Fies sobre o atraso na conclusão do curso de 0,05.

Assim, os resultados indicaram, de uma forma geral, que o Fies, tal como foi desenhado, elevou o tempo que aluno esteve ligado à instituição de ensino superior, seja pelo tempo de conclusão como pelo atraso na conclusão. Conforme destacado por Arendt (2013) e Garibaldi et al. (2012), a ajuda financeira, por tornar menos dispendioso permanecer na educação, pode aumentar o tempo de conclusão do curso e, por isso, é importante que a política tenha mecanismos para incentivar que o aluno conclua o curso no tempo regular. 


\section{Conclusão}

Esse estudo avaliou o impacto do Fies no tempo total e no atraso na conclusão da educação superior dos alunos matriculados em cursos presenciais de instituições privadas, nas duas primeiras fases da política, de 2000 a 2009 e de 2010 a 2014, com base nas informações do Inep de 2007 a 2017.

Os resultados apontaram a presença de um efeito não desejado, uma vez que as estimativas do ATT indicaram, de modo geral, que a participação no Fies aumentou o tempo de conclusão do curso de graduação. Em ambas as fases analisadas, o impacto estimado por score de propensão do Fies no tempo total foi em torno de 4 meses. Os resultados da variável atraso também indicaram um impacto positivo do Fies, porém em menor intensidade, uma vez que a participação na primeira fase do programa aumentou em menos de um mês o atraso na conclusão do curso, além do tempo mínimo. Na segunda fase muitos dos resultados não foram significativos.

Destaca-se ainda que, na segunda fase, os testes não indicaram a qualidade do balanceamento dos grupos. A dificuldade para realizar o pareamento adequado pode estar associada ao fato de que o aluno que solicita Fies no Brasil possui restrições de renda na família e dificilmente teria acesso à educação superior sem o financiamento. A análise de médias e dos resultados do modelo de probabilidade de participação do Fies, utilizado para realizar o pareamento, indicaram que o critério de elegibilidade com base na renda implementado na segunda fase pode ter contribuído para a maior focalização do empréstimo naqueles que mais necessitam, dificultando a identificação das unidades de controle com as mesmas características das unidades de tratamento. Além disso, outros fatores que não podem ser controlados, como condições de vida e saúde na família, podem estar associados à probabilidade de participação no programa e, dessa forma, afetar os resultados. As estimativas do método de Lewbel (2012) para o efeito do Fies no tempo de conclusão foram de 3 meses na primeira fase e 1 mês na segunda fase, o que pode indicar uma possível superestimação dos resultados quando não são consideradas as características não observadas dos alunos.

Ressalvadas essas limitações, de modo geral, os resultados desse estudo somam-se às evidências da literatura de que a estrutura do Fies nas duas primeiras fases, embora tenha elevado o número de matrículas, não produziu resultados benéficos, uma vez que esse crescimento se deu em um ritmo incompatível com a disponibilidade de recursos públicos. Diante disso, foi necessário reavaliar o Fies para uma reestruturação da política ${ }^{3}$. O diagnóstico apontou que a distribuição ineficiente do risco de crédito fez com que este se concentrasse quase todo na União, pois a contribuição das instituições de ensino superior para o Fundo de Garantia de Operações de Crédito Educativo era inferior a $10 \%$ do financiamento concedido pelo Fies e não variava com a performance das carteiras de alunos financiados.

Esse processo levou ao aumento na inadimplência e, além disso, pode ter um efeito indireto sobre o tempo total e o atraso na conclusão do curso, uma vez que a ajuda financeira torna a

(3) Por meio do Acórdão n. 3.001/2016, o Tribunal de Contas da União (TCU) determinou ao MEC, ao Fundo Nacional de Desenvolvimento da Educação (FNDE) e ao Ministério do Planejamento, Desenvolvimento e Gestão (MP) (atualmente incorporado ao Ministério da Economia) que, dentre outras atribuições, elaborassem um plano de trabalho visando à sustentabilidade do Fies. Posteriormente, por meio do Acórdão n. 539/2017, o TCU incluiu o Ministério da Fazenda (MF) na relação de órgãos e entidades responsáveis pelo cumprimento do referido plano de trabalho. 
permanência no curso menos dispendiosa, principalmente na ausência de mecanismos adequados para garantir o pagamento do empréstimo. Nesse contexto, é possível que a reformulação estrutural do Fies em 2015, que elevou os juros e incluiu critérios de elegibilidade mais restritivos para o empréstimo, pode funcionar também como uma forma de mecanismo de incentivo para que o aluno conclua o curso no tempo regular. Em 2018, o programa foi novamente reestruturado com o objetivo de tornar a concessão sustentável do ponto de vista das finanças públicas.

Apesar dos problemas apontados, não se pode descartar o uso do crédito estudantil subsidiado para estudantes de baixa renda, cujo acesso ao crédito privado em circunstâncias puras de mercado não é viável, de modo que esse estudante dificilmente teria acesso à educação superior na ausência de programas como o Fies. Portanto, há um forte apelo social envolvido, na medida em que o Fies pode ser usado como instrumento de mitigação para a acentuada desigualdade social existente no Brasil. Assim, evidencia-se a necessidade das reformulações que houve na política após 2015, de forma a garantir a sustentabilidade fiscal e a sua continuidade, e, também, a necessidade de acrescentar mecanismos de incentivos para que os alunos produzam bons resultados e concluam o curso no tempo regular.

\section{Referências bibliográficas}

ANGRIST, J. D.; PISCHKE, J. Mostly harmless econometrics: an empiricist's companion. Princeton university press, 2009.

ANGRIST, J. D.; AUTOR, D.; HUDSON, S. Leveling up: early results from a randomized evaluation of post-secondary aid. NBER, Dec. 31, 2014. (Working Paper. n. 20800).

ARENDT, J. N. The effect of public financial aid on dropout from and completion of university education: evidence from a student grant reform. Empirical Economics, v. 44, n. 3, p 1545-1556, Jun. 2013

BARBOSA FILHO, F. H.; PESSOA, S. A. Educação e crescimento: o que a evidência empírica e teórica mostra? Revista Economia, Brasília,DF, v. 11, n. 2, p. 265-303, 2010.

BECKER, G. Investment in human capital: a theoretical analysis. Part 2: Investment in human beings. Journal of Political Economy, v. 70, n. 5, p. 9-49, Oct. 1962.

BECKER, G. S. Human capital and the personal distribution of income: an analytical approach. Institute of Public Administration, 1967.

BECKER, G.; TOMES, N. Human capital and the rise and fall of families. Journal of Labor Economics, v. 4, n. 3, p. S1-S39, 1986.

BECKER, K. L. Analysis of math test score gap between white and non-white students in Brazilian public schools - Saeb 2015. UFSM, 2018. (Texto para Discussão). Disponível em: http://coral.ufsm.br/economia.

BELLEY, P.; LOCHNER, L. The changing role of family income and ability in determining educational achievement, Journal of Human Capital, v. 1, n. 1, p. 37-89, 2007. 
CACCIAMALI, M. C.; TATEI, F.; BATISTA, N. F. Impactos do programa bolsa família federal sobre o trabalho infantil e a frequência escolar. Revista de Economia Contemporânea, Rio de Janeiro, v. 14, n. 2, p. 269-301, maio/ago. 2010.

CAMERON, S. V.; TABER C. Estimation of educational borrowing constraints using returns to schooling. Journal of Political Economy, v. 112, n. 1, p. 132-182, Feb. 2004.

CHADAREVIAN, P. C. Para medir as desigualdades raciais no mercado de trabalho Revista de Economia Política, v. 31, n. 2 (122), p. 283-304, abr.jun. 2011.

CRESPO, A.; REIS, M. C. Sheepskin effects and the relationship between earnings and education: analyzing their evolution over time in Brazil. Revista Brasileira de Economia, Rio de Janeiro, v. 63, n. 3, Jul./Set. 2009.

DEHEJIA, R. H.; WAHBA, S. Propensity score-matching methods for nonexperimental causal studies. Review of Economics and Statistics, v. 84, n. 1, p. 151-161, 2002.

DESJARDINS, S.; AHLBURG, D.; MCCALL, B. A temporal investigation of factors related to timely degree completion. The Journal of Higher Education, v. 73, n. 5, p. 555-581, Sept./Oct. 2002.

DYNARSKI, S. Does aid matter? Measuring the effect of student aid on college attendance and completion. American Economic Review, v. 93, n. 1, p. 279-288, 2003.

DUARTE, I. F.; MELLO, J. M. P. Impactos de Financiamento Estudantil sobre encargos escolares: consequências do FIES. Sociedade Brasileira de Econometria, 2014. Disponível em: https://editorialexpress.com/cgibin/conference/download.cgi?db_name=SBE36\&paper_id=205.

ELSAYED, M. A. A. The impact of education tax benefits on college completion. Economics of Education Review, v. 53, p. 16-30, Aug. 2016.

EMRAN, M. S.; HOU, Z. Access to markets and rural poverty: evidence from household consumption in China. The Review of Economics and Statistics, v. 95, n. 2, p. 682-697, 2013.

GARIBALDI, P.; GIAVAZZI, F.; ICHINO, A.; RETTORE. E. College cost and time to complete a degree: evidence from tuition discontinuities. Review of Economics and Statistics, v. 94, n. 3, p. 699711, Aug. 2012.

HAINMUELLER, J. Entropy balancing for causal effects: a multivariate reweighting method to produce balanced samples in observational studies. Political Analysis, v. 20, p. 25-46, 2012.

ISHITANI, T. T. Studying attrition and degree completion behavior among first-generation college students in the United States. The Journal of Higher Education, v. 77, n. 5, p. 861-885, Sep./Oct. 2006.

JACOBY, H. Borrowing constraints and progress through school: evidence from Peru. The Review of Economics and Statistics, v. 76, n. 1, p. 151-160, 1994.

KANE, T. J. A. Quasi-experimental estimate of the impact of financial aid on college-going. NBER, 2003. (Working Paper, n. 9703). 
LEWBEL, A. Using heteroscedasticity to identify and estimate mismeasured and endogenous regressor models. Journal of Business and Economic Statistics, v. 30, p. 67-80, 2012.

LEWBEL, A. Identification and estimation using heteroscedasticity without instruments: the binary endogenous regressor case. Boston College, 2016.

LJUNGQVIST, L. Economic underdevelopment: the case of a missing market for human capital. Journal of Development Economics, v. 40, n. 2, p. 219-239, 1993.

LOCHNER, L. J.; MONGE-NARANJO, A. Credit constraints in education. NBER, 2011. (Working Papers, n. 17435).

LOURY, G. Intergenerational transfers and the distribution of earnings. Econometrica, p. 843-867, 1981.

MELGUIZO, T.; SANCHEZ, F.; VELASCO, T. Credit for low-income students and access to and academic performance in higher education in Colombia: a regression discontinuity approach. World Development, v. 80, p. 61-77, Apr. 2016.

SOUZA, W. P. S. F.; MESQUITA, S. P.; OLIVEIRA, V. R.; SILVA, M. E. L. Trabalho infantil e programas de transferência de renda: uma análise do impacto do Programa Bolsa Família nas zonas urbana e rural do Brasil. Pesquisa e Planejamento Econômico, v. 49, n. 2, ago. 2019.

MINISTÉRIO DA FAZENDA. Fundo de Financiamento Estudantil: ausência de sustentabilidade fiscal e suas causas. Diagnóstico do Fies, jun. 2017.

OECD. Education at a Glance 2018: OECD Indicators. Paris: OECD Publishing, 2018.

OLIVEIRA, P. R.; BELLUZZO, W.; PAZELLO, E. T. The public-private test score gap in Brazil. Economics of Education Review, 35, p. 120-133, 2013.

PONTUSCHKA, R. Avaliação de impacto do Fies. Dissertação (Mestrado)-Escola Superior de Agricultura “Luiz de Queiroz”. Programa de Pós Graduação em Economia Aplicada, 2016.

RAU, T.; ROJAS, E.; URZUA, S. Higher education dropouts, access to credit, and labor market outcomes: evidence from Chile. 2012. Mimeo. Disponível em: http://conference.iza.org/conference_files/Eval2012/urzua_s3056.pdf.

REIS, M. C.; RAMOS, L. Escolaridade dos pais, desempenho no mercado de trabalho e desigualdade de rendimentos. Revista Brasileira de Economia, Rio de Janeiro, v. 65, n. 2, abr./jun. 2011.

RESENDE, M. V. A. Crédito educativo: uma análise comparada sobre focalização e sustentabilidade financeira em programas de financiamento estudantil no Brasil, Estados Unidos e Austrália. Dissertação (Mestrado)-Instituto de Pesquisa Econômica Aplicada (IPEA). Programa de PósGraduação em Políticas Públicas e Desenvolvimento, 2018.

ROCHA, I. C. Investimento endógeno em capital humano em um modelo de gerações sobrepostas com restrição de crédito e consumo mínimo. Dissertação (Mestrado)-Universidade de Brasília. PósGraduação em Economia, 2014. 
ROCHA, W. Análise de impacto do Fies sobre a renda do trabalhador formal. Dissertação (Mestrado)-Universidade Católica de Brasília. Programa de Pós Graduação em Economia, 2016.

ROSENBAUM, P.; RUBIN, D. Constructing a control group using multivariate matched sampling methods that incorporate the propensity score. The American Statistician, v. 39, n. 1, p. 33-38, 1985.

ROSENBAUM, P.; RUBIN, D. The central role of the propensity score in observational studies for causal effects. Biometrika, 70, p. 41-50, 1983.

RUBIN, D. Estimating causal effect to treatments in randomised and nonrandomised studies. Journal of Educational Psychology, 66, p. 688-701, 1974.

TESOURO NACIONAL. Financiamento estudantil: indicadores e insights sobre a focalização do programa. Boletim de Avaliação de Políticas Públicas, v. 1, n. 2, jul. 2015.

TIGRE, R.; SAMPAIO, B.; MENEZES, T. The impact of commuting time on youth's school performance. Journal of Regional Science, 2016. 


\section{Apêndice 1}

Balanceamento por score de propensão - Fies $1^{\text {a }}$. Fase

\begin{tabular}{|c|c|c|c|c|c|c|c|c|}
\hline & \multicolumn{4}{|c|}{ Antes do pareamento } & \multicolumn{4}{|c|}{ Depois do pareamento $-\mathrm{Nn}(5)$} \\
\hline & Tratam. & Contr. & Dif. & $p$-valor & Tratam. & Contr. & Dif. & $p$-valor \\
\hline Idade & 27,954 & 27,751 & 0,203 & 0,001 & 27,954 & 27,893 & 0,061 & 0,451 \\
\hline Homem & 0,387 & 0,402 & $-0,014$ & 0,000 & 0,387 & 0,385 & 0,002 & 0,677 \\
\hline Cor 1 (preto) & 0,083 & 0,061 & 0,023 & 0,000 & 0,083 & 0,082 & 0,002 & 0,606 \\
\hline Cor 2 (pardo) & 0,263 & 0,221 & 0,042 & 0,000 & 0,263 & 0,264 & $-0,001$ & 0,873 \\
\hline Cor 3 (amar.) & 0,014 & 0,018 & $-0,004$ & 0,000 & 0,014 & 0,013 & 0,001 & 0,459 \\
\hline Cor 4 (indig.) & 0,009 & 0,008 & 0,001 & 0,481 & 0,009 & 0,009 & 0,000 & 0,943 \\
\hline Escpai 1 (EF) & 0,171 & 0,159 & 0,012 & 0,000 & 0,171 & 0,167 & 0,004 & 0,371 \\
\hline Escpai 2 (EM) & 0,296 & 0,290 & 0,006 & 0,111 & 0,296 & 0,298 & $-0,003$ & 0,622 \\
\hline Escpai 3 (ES) & 0,145 & 0,198 & $-0,053$ & 0,000 & 0,145 & 0,145 & $-0,001$ & 0,887 \\
\hline Escmãe $1(\mathrm{EF})$ & 0,169 & 0,167 & 0,002 & 0,556 & 0,169 & 0,167 & 0,002 & 0,698 \\
\hline Escmãe 2 (EM) & 0,317 & 0,308 & 0,009 & 0,017 & 0,317 & 0,318 & $-0,001$ & 0,825 \\
\hline Escmãe 3 (ES) & 0,185 & 0,207 & $-0,023$ & 0,000 & 0,185 & 0,186 & $-0,001$ & 0,834 \\
\hline Estcivil 1 (cas.) & 0,222 & 0,231 & $-0,009$ & 0,008 & 0,222 & 0,219 & 0,003 & 0,479 \\
\hline Estcivil 2 (sep.) & 0,078 & 0,066 & 0,013 & 0,000 & 0,078 & 0,076 & 0,002 & 0,550 \\
\hline Cmora. 1 (pais) & 0,302 & 0,262 & 0,040 & 0,000 & 0,302 & 0,301 & 0,001 & 0,903 \\
\hline Cmora. 2 (conj) & 0,441 & 0,495 & $-0,054$ & 0,000 & 0,441 & 0,446 & $-0,004$ & 0,434 \\
\hline Cmora. 3 (rep.) & 0,234 & 0,224 & 0,010 & 0,002 & 0,234 & 0,232 & 0,003 & 0,577 \\
\hline Trabalha & 0,697 & 0,752 & $-0,055$ & 0,000 & 0,697 & 0,696 & 0,000 & 0,961 \\
\hline RF 1 (3 a 10) & 0,520 & 0,530 & $-0,010$ & 0,016 & 0,520 & 0,524 & $-0,003$ & 0,566 \\
\hline RF 2 (10 a 30) & 0,090 & 0,189 & $-0,099$ & 0,000 & 0,090 & 0,091 & $-0,001$ & 0,666 \\
\hline Sit. Fin. 1 & 0,344 & 0,349 & $-0,006$ & 0,129 & 0,344 & 0,345 & $-0,001$ & 0,845 \\
\hline Sit. Fin. 2 & 0,175 & 0,202 & $-0,027$ & 0,000 & 0,175 & 0,175 & $-0,001$ & 0,902 \\
\hline Sit. Fin. 3 & 0,215 & 0,236 & $-0,021$ & 0,000 & 0,215 & 0,213 & 0,002 & 0,671 \\
\hline EM esc. Pub. & 0,713 & 0,657 & 0,056 & 0,000 & 0,713 & 0,713 & 0,000 & 0,923 \\
\hline M.EM1(Profis.) & 0,226 & 0,213 & 0,013 & 0,000 & 0,226 & 0,219 & 0,006 & 0,165 \\
\hline M. EM2(Mag.) & 0,065 & 0,056 & 0,008 & 0,000 & 0,065 & 0,063 & 0,001 & 0,593 \\
\hline Noturno & 0,735 & 0,785 & $-0,051$ & 0,000 & 0,735 & 0,737 & $-0,002$ & 0,654 \\
\hline T IES 1 (CU) & 0,206 & 0,205 & 0,001 & 0,667 & 0,206 & 0,206 & 0,000 & 1,000 \\
\hline T IES 2 (Facul.) & 0,470 & 0,397 & 0,073 & 0,000 & 0,470 & 0,471 & $-0,001$ & 0,863 \\
\hline Área conh. 1 & 0,197 & 0,217 & $-0,020$ & 0,000 & 0,197 & 0,198 & $-0,001$ & 0,809 \\
\hline Área conh. 2 & 0,566 & 0,646 & $-0,080$ & 0,000 & 0,566 & 0,567 & $-0,002$ & 0,783 \\
\hline IGC & 2,818 & 2,829 & $-0,010$ & 0,012 & 2,818 & 2,819 & $-0,001$ & 0,905 \\
\hline Reg. 1 & 0,225 & 0,114 & 0,111 & 0,000 & 0,225 & 0,230 & $-0,005$ & 0,283 \\
\hline Reg. 2 & 0,429 & 0,591 & $-0,162$ & 0,000 & 0,429 & 0,425 & 0,004 & 0,446 \\
\hline Reg. 3 & 0,226 & 0,181 & 0,045 & 0,000 & 0,226 & 0,225 & 0,001 & 0,860 \\
\hline Reg. 4 & 0,072 & 0,078 & $-0,006$ & 0,008 & 0,072 & 0,073 & 0,000 & 0,925 \\
\hline Observações & 16.051 & 232.860 & & & 16.051 & 232.860 & & \\
\hline
\end{tabular}




\section{Apêndice 2}

Balanceamento por score de propensão - Fies $2^{\mathrm{a}}$. Fase

\begin{tabular}{|c|c|c|c|c|c|c|c|c|}
\hline & \multicolumn{4}{|c|}{ Antes do pareamento } & \multicolumn{4}{|c|}{ Depois do pareamento - $\mathrm{Nn}(5)$} \\
\hline & Tratam. & Contr. & Dif. & $p$-valor & Tratam. & Contr. & Dif. & $p$-valor \\
\hline Idade & 28,148 & 27,568 & 0,580 & 0,000 & 28,148 & 27,975 & 0,173 & 0,000 \\
\hline Homem & 0,379 & 0,404 & $-0,025$ & 0,000 & 0,379 & 0,372 & 0,007 & 0,000 \\
\hline Cor 1 (preto) & 0,100 & 0,082 & 0,018 & 0,000 & 0,100 & 0,098 & 0,002 & 0,021 \\
\hline Cor 2 (pardo) & 0,368 & 0,300 & 0,067 & 0,000 & 0,368 & 0,367 & 0,001 & 0,579 \\
\hline Cor 3 (amar.) & 0,022 & 0,020 & 0,001 & 0,000 & 0,022 & 0,020 & 0,002 & 0,000 \\
\hline Cor 4 (indig.) & 0,005 & 0,006 & $-0,001$ & 0,000 & 0,005 & 0,005 & 0,000 & 0,610 \\
\hline Escpai $1(\mathrm{EF})$ & 0,166 & 0,158 & 0,008 & 0,000 & 0,166 & 0,164 & 0,001 & 0,206 \\
\hline Escpai 2 (EM) & 0,315 & 0,320 & $-0,005$ & 0,000 & 0,315 & 0,318 & $-0,003$ & 0,052 \\
\hline Escpai 3 (ES) & 0,135 & 0,185 & $-0,050$ & 0,000 & 0,135 & 0,134 & 0,001 & 0,263 \\
\hline Escmãe 1 (EF) & 0,165 & 0,160 & 0,005 & 0,000 & 0,165 & 0,162 & 0,003 & 0,003 \\
\hline Escmãe 2 (EM) & 0,332 & 0,335 & $-0,003$ & 0,006 & 0,332 & 0,335 & $-0,003$ & 0,035 \\
\hline Escmãe 3 (ES) & 0,188 & 0,220 & $-0,032$ & 0,000 & 0,188 & 0,188 & 0,000 & 0,740 \\
\hline Estcivil 1 (cas.) & 0,224 & 0,218 & 0,007 & 0,000 & 0,224 & 0,218 & 0,006 & 0,000 \\
\hline Estcivil 2 (sep.) & 0,074 & 0,061 & 0,013 & 0,000 & 0,074 & 0,071 & 0,003 & 0,001 \\
\hline Cmora. 1 (pais) & 0,560 & 0,611 & $-0,051$ & 0,000 & 0,560 & 0,571 & $-0,011$ & 0,000 \\
\hline Cmora. 2 (conj) & 0,299 & 0,276 & 0,024 & 0,000 & 0,299 & 0,290 & 0,009 & 0,000 \\
\hline Cmora. 3 (rep.) & 0,056 & 0,042 & 0,014 & 0,000 & 0,056 & 0,058 & $-0,002$ & 0,022 \\
\hline Trabalha & 0,589 & 0,683 & $-0,094$ & 0,000 & 0,589 & 0,584 & 0,005 & 0,000 \\
\hline RF 1 (3 a 10) & 0,406 & 0,519 & $-0,113$ & 0,000 & 0,406 & 0,407 & $-0,001$ & 0,585 \\
\hline RF 2 (10 a 30) & 0,030 & 0,105 & $-0,075$ & 0,000 & 0,030 & 0,029 & 0,001 & 0,179 \\
\hline Sit. Fin. 1 & 0,247 & 0,294 & $-0,047$ & 0,000 & 0,247 & 0,249 & $-0,002$ & 0,141 \\
\hline Sit. Fin. 2 & 0,081 & 0,152 & $-0,071$ & 0,000 & 0,081 & 0,078 & 0,003 & 0,001 \\
\hline Sit. Fin. 3 & 0,263 & 0,234 & 0,029 & 0,000 & 0,263 & 0,263 & 0,000 & 0,867 \\
\hline EM esc. Pub. & 0,781 & 0,710 & 0,071 & 0,000 & 0,781 & 0,788 & $-0,006$ & 0,000 \\
\hline M.EM1(Profis.) & 0,096 & 0,121 & $-0,025$ & 0,000 & 0,096 & 0,093 & 0,003 & 0,001 \\
\hline M. EM2(Mag.) & 0,074 & 0,060 & 0,014 & 0,000 & 0,074 & 0,071 & 0,004 & 0,000 \\
\hline Noturno & 0,750 & 0,779 & $-0,029$ & 0,000 & 0,750 & 0,750 & 0,000 & 0,924 \\
\hline T IES 1 (CU) & 0,199 & 0,174 & 0,025 & 0,000 & 0,199 & 0,188 & 0,011 & 0,000 \\
\hline T IES 2 (Facul.) & 0,517 & 0,444 & 0,073 & 0,000 & 0,517 & 0,526 & $-0,008$ & 0,000 \\
\hline Área conh. 1 & 0,377 & 0,315 & 0,062 & 0,000 & 0,377 & 0,375 & 0,002 & 0,202 \\
\hline Área conh. 2 & 0,335 & 0,507 & $-0,173$ & 0,000 & 0,335 & 0,335 & $-0,001$ & 0,637 \\
\hline IGC & 3,163 & 3,154 & 0,008 & 0,000 & 3,163 & 3,163 & 0,000 & 0,974 \\
\hline Reg. 1 & 0,235 & 0,151 & 0,084 & 0,000 & 0,235 & 0,235 & 0,001 & 0,614 \\
\hline Reg. 2 & 0,453 & 0,550 & $-0,097$ & 0,000 & 0,453 & 0,452 & 0,001 & 0,427 \\
\hline Reg. 3 & 0,144 & 0,164 & $-0,020$ & 0,000 & 0,144 & 0,148 & $-0,004$ & 0,001 \\
\hline Reg. 4 & 0,105 & 0,083 & 0,022 & 0,000 & 0,105 & 0,105 & 0,000 & 0,650 \\
\hline Observações & 211.335 & 605.342 & & & 211.335 & 605.342 & & \\
\hline
\end{tabular}




\section{Apêndice 3}

Balanceamento por Entropia - Fies $1^{\mathrm{a}}$. Fase

\begin{tabular}{|c|c|c|c|c|c|c|c|c|}
\hline \multirow{3}{*}{ Controles } & \multicolumn{4}{|c|}{ Antes } & \multicolumn{4}{|c|}{ Depois } \\
\hline & \multicolumn{2}{|c|}{ Tratamento } & \multicolumn{2}{|c|}{ Controle } & \multicolumn{2}{|c|}{ Tratamento } & \multicolumn{2}{|c|}{ Controle } \\
\hline & Média & Variância & Média & Variância & Média & Variância & Média & Variância \\
\hline Idade & 27,954 & 45,880 & 27,751 & 57,270 & 27,950 & 45,880 & 27,950 & 58,780 \\
\hline Homem & 0,388 & 0,237 & 0,402 & 0,240 & 0,388 & 0,237 & 0,388 & 0,237 \\
\hline Cor 1 (preto) & 0,083 & 0,076 & 0,061 & 0,057 & 0,083 & 0,076 & 0,083 & 0,076 \\
\hline Cor 2 (pardo) & 0,263 & 0,194 & 0,221 & 0,172 & 0,263 & 0,194 & 0,263 & 0,194 \\
\hline Cor 3 (amar.) & 0,014 & 0,014 & 0,018 & 0,018 & 0,014 & 0,014 & 0,014 & 0,014 \\
\hline Cor 4 (indig.) & 0,009 & 0,009 & 0,008 & 0,008 & 0,009 & 0,009 & 0,009 & 0,009 \\
\hline Escpai 1 (EF) & 0,171 & 0,142 & 0,159 & 0,134 & 0,171 & 0,142 & 0,171 & 0,142 \\
\hline Escpai 2 (EM) & 0,296 & 0,208 & 0,290 & 0,206 & 0,296 & 0,208 & 0,296 & 0,208 \\
\hline Escpai 3 (ES) & 0,145 & 0,124 & 0,198 & 0,159 & 0,145 & 0,124 & 0,145 & 0,124 \\
\hline Escmãe 1 (EF) & 0,169 & 0,140 & 0,167 & 0,139 & 0,169 & 0,140 & 0,169 & 0,140 \\
\hline Escmãe 2 (EM) & 0,317 & 0,216 & 0,308 & 0,213 & 0,317 & 0,216 & 0,317 & 0,216 \\
\hline Escmãe 3 (ES) & 0,185 & 0,151 & 0,208 & 0,164 & 0,185 & 0,151 & 0,185 & 0,151 \\
\hline Estcivil 1 (cas.) & 0,222 & 0,173 & 0,231 & 0,178 & 0,222 & 0,173 & 0,222 & 0,173 \\
\hline Estcivil 2 (sep.) & 0,078 & 0,072 & 0,066 & 0,061 & 0,078 & 0,072 & 0,078 & 0,072 \\
\hline Cmora. 1 (pais) & 0,302 & 0,211 & 0,262 & 0,193 & 0,302 & 0,211 & 0,302 & 0,211 \\
\hline Cmora. 2 (conj) & 0,441 & 0,247 & 0,495 & 0,250 & 0,441 & 0,247 & 0,442 & 0,247 \\
\hline Cmora. 3 (rep.) & 0,234 & 0,179 & 0,224 & 0,174 & 0,234 & 0,179 & 0,234 & 0,179 \\
\hline Trabalha & 0,697 & 0,211 & 0,752 & 0,187 & 0,697 & 0,211 & 0,697 & 0,211 \\
\hline RF 1 (3 a 10) & 0,520 & 0,250 & 0,530 & 0,249 & 0,520 & 0,250 & 0,520 & 0,250 \\
\hline RF 2 (10 a 30) & 0,090 & 0,082 & 0,189 & 0,153 & 0,090 & 0,082 & 0,091 & 0,083 \\
\hline Sit. Fin. 1 & 0,344 & 0,226 & 0,349 & 0,227 & 0,344 & 0,226 & 0,344 & 0,226 \\
\hline Sit. Fin. 2 & 0,175 & 0,144 & 0,202 & 0,161 & 0,175 & 0,144 & 0,175 & 0,144 \\
\hline Sit. Fin. 3 & 0,215 & 0,169 & 0,236 & 0,180 & 0,215 & 0,169 & 0,215 & 0,169 \\
\hline EM esc. Pub. & 0,713 & 0,205 & 0,657 & 0,225 & 0,713 & 0,205 & 0,713 & 0,205 \\
\hline M.EM1(Profis.) & 0,226 & 0,175 & 0,213 & 0,168 & 0,226 & 0,175 & 0,226 & 0,175 \\
\hline M. EM2(Mag.) & 0,065 & 0,060 & 0,056 & 0,053 & 0,065 & 0,060 & 0,065 & 0,060 \\
\hline Noturno & 0,735 & 0,195 & 0,785 & 0,169 & 0,735 & 0,195 & 0,735 & 0,195 \\
\hline T IES 1 (CU) & 0,206 & 0,164 & 0,205 & 0,163 & 0,206 & 0,164 & 0,206 & 0,164 \\
\hline T IES 2 (Facul.) & 0,470 & 0,249 & 0,397 & 0,239 & 0,470 & 0,249 & 0,469 & 0,249 \\
\hline Área conh. 1 & 0,197 & 0,158 & 0,217 & 0,170 & 0,197 & 0,158 & 0,197 & 0,158 \\
\hline Área conh. 2 & 0,566 & 0,246 & 0,646 & 0,229 & 0,566 & 0,246 & 0,566 & 0,246 \\
\hline IGC & 2,818 & 0,248 & 2,828 & 0,260 & 2,818 & 0,248 & 2,818 & 0,266 \\
\hline Reg. 1 & 0,225 & 0,175 & 0,114 & 0,101 & 0,225 & 0,175 & 0,225 & 0,174 \\
\hline Reg. 2 & 0,429 & 0,245 & 0,591 & 0,242 & 0,429 & 0,245 & 0,430 & 0,245 \\
\hline Reg. 3 & 0,226 & 0,175 & 0,181 & 0,148 & 0,226 & 0,175 & 0,226 & 0,175 \\
\hline Reg. 4 & 0,072 & 0,067 & 0,078 & 0,072 & 0,072 & 0,067 & 0,072 & 0,067 \\
\hline Observações & \multicolumn{2}{|c|}{16.051} & \multicolumn{2}{|c|}{232.860} & & 16.051 & \multicolumn{2}{|c|}{232.860} \\
\hline
\end{tabular}




\section{Apêndice 4}

Balanceamento por Entropia - Fies $2^{\text {a }}$. Fase

\begin{tabular}{|c|c|c|c|c|c|c|c|c|}
\hline \multirow{3}{*}{ Controles } & \multicolumn{4}{|c|}{ Antes } & \multicolumn{4}{|c|}{ Depois } \\
\hline & \multicolumn{2}{|c|}{ Tratamento } & \multicolumn{2}{|c|}{ Controle } & \multicolumn{2}{|c|}{ Tratamento } & \multicolumn{2}{|c|}{ Controle } \\
\hline & Média & Variância & Média & Variância & Média & Variância & Média & Variância \\
\hline Idade & 28,148 & 51,550 & 27,568 & 55,590 & 28,150 & 51,550 & 28,150 & 61,040 \\
\hline Homem & 0,379 & 0,235 & 0,404 & 0,241 & 0,379 & 0,235 & 0,379 & 0,235 \\
\hline Cor 1 (preto) & 0,100 & 0,090 & 0,082 & 0,075 & 0,100 & 0,090 & 0,100 & 0,090 \\
\hline Cor 2 (pardo) & 0,368 & 0,233 & 0,300 & 0,210 & 0,368 & 0,233 & 0,367 & 0,232 \\
\hline Cor 3 (amar.) & 0,022 & 0,021 & 0,020 & 0,020 & 0,022 & 0,021 & 0,022 & 0,021 \\
\hline Cor 4 (indig.) & 0,005 & 0,005 & 0,006 & 0,006 & 0,005 & 0,005 & 0,005 & 0,005 \\
\hline Escpai 1 (EF) & 0,166 & 0,138 & 0,158 & 0,133 & 0,166 & 0,138 & 0,166 & 0,138 \\
\hline Escpai 2 (EM) & 0,315 & 0,216 & 0,320 & 0,218 & 0,315 & 0,216 & 0,315 & 0,216 \\
\hline Escpai 3 (ES) & 0,135 & 0,117 & 0,185 & 0,151 & 0,135 & 0,117 & 0,136 & 0,117 \\
\hline Escmãe 1 (EF) & 0,165 & 0,138 & 0,160 & 0,134 & 0,165 & 0,138 & 0,165 & 0,138 \\
\hline Escmãe 2 (EM) & 0,332 & 0,222 & 0,336 & 0,223 & 0,332 & 0,222 & 0,332 & 0,222 \\
\hline Escmãe 3 (ES) & 0,188 & 0,153 & 0,220 & 0,172 & 0,188 & 0,153 & 0,188 & 0,153 \\
\hline Estcivil 1 (cas.) & 0,224 & 0,174 & 0,218 & 0,170 & 0,224 & 0,174 & 0,224 & 0,174 \\
\hline Estcivil 2 (sep.) & 0,074 & 0,069 & 0,061 & 0,057 & 0,074 & 0,069 & 0,074 & 0,069 \\
\hline Cmora. 1 (pais) & 0,560 & 0,246 & 0,611 & 0,238 & 0,560 & 0,246 & 0,560 & 0,246 \\
\hline Cmora. 2 (conj) & 0,300 & 0,210 & 0,276 & 0,200 & 0,300 & 0,210 & 0,299 & 0,210 \\
\hline Cmora. 3 (rep.) & 0,056 & 0,053 & 0,042 & 0,040 & 0,056 & 0,053 & 0,056 & 0,053 \\
\hline Trabalha & 0,589 & 0,242 & 0,683 & 0,217 & 0,589 & 0,242 & 0,590 & 0,242 \\
\hline RF 1 (3 a 10) & 0,406 & 0,241 & 0,519 & 0,250 & 0,406 & 0,241 & 0,406 & 0,241 \\
\hline RF 2 (10 a 30) & 0,030 & 0,029 & 0,105 & 0,094 & 0,030 & 0,029 & 0,031 & 0,030 \\
\hline Sit. Fin. 1 & 0,247 & 0,186 & 0,294 & 0,208 & 0,247 & 0,186 & 0,247 & 0,186 \\
\hline Sit. Fin. 2 & 0,081 & 0,074 & 0,152 & 0,129 & 0,081 & 0,074 & 0,081 & 0,075 \\
\hline Sit. Fin. 3 & 0,263 & 0,194 & 0,234 & 0,179 & 0,263 & 0,194 & 0,263 & 0,194 \\
\hline EM esc. Pub. & 0,781 & 0,171 & 0,710 & 0,206 & 0,781 & 0,171 & 0,781 & 0,171 \\
\hline M.EM1(Profis.) & 0,096 & 0,087 & 0,121 & 0,106 & 0,096 & 0,087 & 0,096 & 0,087 \\
\hline M. EM2(Mag.) & 0,074 & 0,069 & 0,060 & 0,057 & 0,074 & 0,069 & 0,074 & 0,069 \\
\hline Noturno & 0,750 & 0,187 & 0,779 & 0,172 & 0,750 & 0,187 & 0,750 & 0,187 \\
\hline T IES 1 (CU) & 0,199 & 0,159 & 0,174 & 0,143 & 0,199 & 0,159 & 0,199 & 0,159 \\
\hline T IES 2 (Facul.) & 0,517 & 0,250 & 0,444 & 0,247 & 0,517 & 0,250 & 0,517 & 0,250 \\
\hline Área conh. 1 & 0,377 & 0,235 & 0,315 & 0,216 & 0,377 & 0,235 & 0,377 & 0,235 \\
\hline Área conh. 2 & 0,335 & 0,223 & 0,507 & 0,250 & 0,335 & 0,223 & 0,335 & 0,223 \\
\hline IGC & 3,163 & 0,217 & 3,154 & 0,231 & 3,163 & 0,217 & 3,163 & 0,236 \\
\hline Reg. 1 & 0,235 & 0,180 & 0,151 & 0,128 & 0,235 & 0,180 & 0,235 & 0,180 \\
\hline Reg. 2 & 0,453 & 0,248 & 0,550 & 0,248 & 0,453 & 0,248 & 0,453 & 0,248 \\
\hline Reg. 3 & 0,144 & 0,123 & 0,164 & 0,137 & 0,144 & 0,123 & 0,144 & 0,123 \\
\hline Reg. 4 & 0,105 & 0,094 & 0,083 & 0,076 & 0,105 & 0,094 & 0,105 & 0,094 \\
\hline Observações & \multicolumn{2}{|c|}{211.335} & \multicolumn{2}{|c|}{605.342} & & 211.335 & \multicolumn{2}{|c|}{605.342} \\
\hline
\end{tabular}

